\title{
Delivering contraceptive vaginal rings: Review of postpartum service packages in Kenya
}

\author{
Wilson Liambila \\ Population Council \\ Saumya RamaRao \\ Population Council \\ Heather Clark \\ Population Council
}

Follow this and additional works at: https://knowledgecommons.popcouncil.org/departments_sbsr-rh

Part of the Demography, Population, and Ecology Commons, Family, Life Course, and Society Commons, International Public Health Commons, Maternal and Child Health Commons, and the Women's Health Commons How does access to this work benefit you? Let us know!

\section{Recommended Citation}

Liambila, Wilson, Saumya RamaRao, and Heather Clark. 2015. "Delivering contraceptive vaginal rings: Review of postpartum service packages in Kenya." Nairobi: Population Council. 


\title{
DELIVERING CONTRACEPTIVE VAGINAL RINGS
}

\section{Review of Postpartum Service Packages in Kenya}

\author{
Wilson Liambila \\ Saumya RamaRao \\ Heather Clark
}




\section{ק户}

The Population Council confronts critical health and development issues-from stopping the spread of HIV to improving reproductive health and ensuring that young people lead full and productive lives. Through biomedical, social science, and public health research in 50 countries, we work with our partners to deliver solutions that lead to more effective policies, programs, and technologies that improve lives around the world. Established in 1952 and headquartered in New York, the Council is a nongovernmental, nonprofit organization governed by an international board of trustees.

Population Council

General Accident House

Ralph Bunche Road

Nairobi

Kenya

Tel: +254202713480

Fax: +254202713479

www.popcouncil.org

Suggested citation: Liambila Wilson, Saumya RamaRao, and Heather Clark. 2015. "Delivering Contraceptive Vaginal Rings: Review of Postpartum Service Packages in Kenya." Nairobi: Population Council. 


\section{Table of Contents}

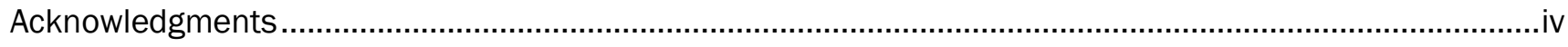

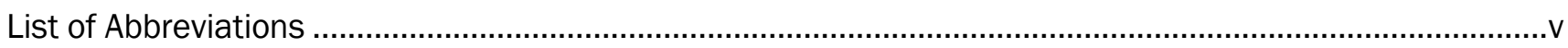

Executive Summary …..............................................................................................................

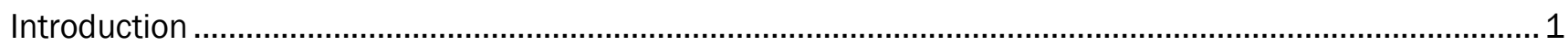

Health System Structures \& Provision of Postnatal Care ......................................................................... 7

Integration of Key RH \& PHC services into Postnatal Care Activities ...................................................14

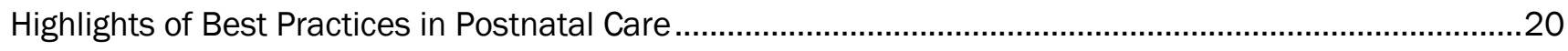

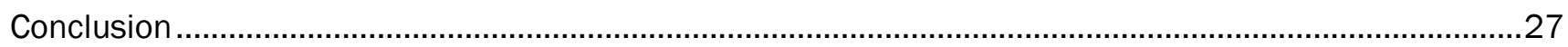

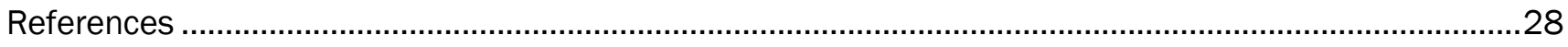

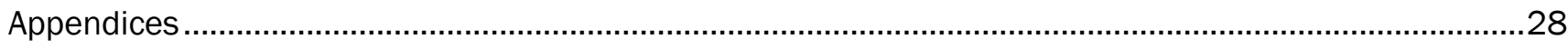




\section{Acknowledgments}

We wish to acknowledge the leadership within the Ministry of Health in Kenya especially the Director of Medical services, Dr. Nicholas Muraguri, Dr. Bartilol Kigen - Head, Reproductive and Maternal Health Services Unit (RMHSU), Dr. Agnes Nakato - Program Manager - Family Planning and Gladys Someren - Program Officer, Family Planning services for their support towards the study on Assessing the Acceptability of a Progesterone Contraceptive Vaginal Ring (PCVR) and the project activities for the program on delivering contraceptive vaginal rings. We sincerely acknowledge health providers from the implementing sites in Kiambu, Murang'a and Nairobi counties for playing leading roles in ensuring that health providers include PCVR as part of the national contraceptive method-mix while counselling clients who sought various family planning methods. We also wish to thank the health management teams of Kiambu, Murang'a and Nairobi counties for providing technical and logistical support to their respective health providers with regard to PCVR related activities. We also wish to thank Carolyne Macharia- Nursing Officer in-charge of Kirwara Sub-County Hospital for her candid views on how to improve postpartum services in Kenya. We also wish to thank the staff who worked in the pilot facilities for implementing project activities related to PCVR.

The following individuals are acknowledged for reviewing the report: Salisu Ishaku, Babacar Mane, John Townsend and lan Askew. Janet Munyasya and Naomi Rijo are acknowledged for providing administrative support.

Finally, we would like to thank USAID for making financial resources available for the implementation of transition activities from the PCVR Acceptability Study to the Service Delivery Phase in Kenya. 


\section{List of Abbreviations}

\begin{tabular}{ll} 
AIDS & Acquired Immunodeficiency Syndrome \\
BTL & Bilateral tubal ligation \\
CBD & Community Based Distributor \\
CBS & Central Bureau of Statistics \\
CHEW & Community Health Extension Worker \\
CHW & Community Health Worker \\
CM & Community Midwife \\
COC & Combined Oral Contraceptives \\
CPR & Contraceptive Prevalence Rate \\
DMPA & Depot Medroxyprogesterone Acetate \\
DRH & Division of Reproductive Health \\
FHI360 & Family Health International 360 \\
FIGO & International Federation of Gynecology and Obstetrics \\
FP & Family Planning \\
GHI & Global Health Initiative \\
HIV & Human Immunodeficiency Virus \\
ICPD & International Conference on Population and Development \\
IUCD & Intrauterine Contraceptive Device \\
KDHS & Kenya Demographic and Health Survey \\
KEPH & Kenya Essential Package for Health \\
KHSSP & Kenya Health Sector Strategic Plan \\
KNBS & Kenya National Bureau of Statistics \\
KOGS & Kenya Obstetrical and Gynaecological Society \\
MNH & Maternal and Newborn Health \\
MOH & Ministry of Health \\
MOMS & Ministry of Medical Services \\
MOPHS & Ministry of Public Health and Sanitation \\
MYWO & Maendeleo Ya Wanawake Organization \\
NCPD & National Council for Population and Development \\
NGO & Non-governmental Organization \\
PCVR & Progesterone Contraceptive Vaginal Ring \\
PNC & Postnatal Care \\
PPC & Postpartum care \\
RH CO & Reproductive Health Clinical Officer \\
TFR & Total Fertility Rate \\
UNFPA & United Nations Population Fund \\
USAID & United States Agency for International Development \\
VMMC & Voluntary Male Medical circumcision \\
WCG & Woman Care Global \\
WHO & World Health Organization \\
\hline
\end{tabular}




\section{Executive Summary}

The postnatal period is a critical phase in the lives of mothers and newborn babies. Most maternal and infant deaths occur during this time. Yet, this is the most neglected period for the coverage and provision of quality care. The health system building blocks of the WHO health systems model were applied in describing the status and health system structures that support the provision of postpartum and postnatal care services in Kenya. The purpose of this approach was to ensure that important aspects of the provision of postpartum care and postnatal care services are assessed as comprehensively as possible. The components assessed are leadership or governance, service delivery, health worker force, information, medical products and financing mechanisms.

Highlights of best practices in postpartum care are presented. Five examples are described:

(a) Post-Partum Intrauterine Contraceptive Device (PPIUCD) in Eastern Province, Kenya

(b) Using community midwives to provide postpartum and postnatal care

(c) Best Practices from the MCHIP/Kenya Program Experiences

(d) Integrating STIs/RTIs into Postnatal care

(e) Integrating tuberculosis screening and detection in postpartum and postnatal care

There are many opportunities for facilitating the delivery of Progesterone contraceptive vaginal rings (PCVR) within PNC services in Kenya such as integration with other primary health care components. Examples include immunization activities, strengthening breast feeding and infant nutrition practices and strengthening post-partum FP services. The other opportunity is the level of policy support for postpartum services as well as postnatal care activities. Current policy-level support for Progesterone contraceptive vaginal rings in Kenya provides an additional opportunity to strengthen postpartum care activities in future. The Ministry of Health policy makers view the PCVR as a very useful product that is meant to widen or broaden the contraceptive options for breastfeeding women in the postpartum period.

There are a number of challenges to be addressed. First, the majority of women in Kenya (over 56\%) still deliver at the community level. Given that about $60 \%$ of the neonatal deaths occur within the first week following childbirth, this means that a substantial proportion of babies and their mothers do not receive quality PNC. Another challenge has to do with inadequate financial resources that are allocated to reproductive health activities. Additional resources will be required to support demandgeneration activities for any new contraceptive product, particularly during the postnatal period when the focus of the mother's attention is on the health of the baby.

In conclusion, the available postnatal care packages provide useful entry points not only for integrating PCVR but also for making it potentially accessible and available in nearly all maternal and newborn points of contact with postnatal clients. The examples highlighted in the area of integration of services as well as those cited under best practices provide opportunities for scaling up PCVR activities within health facilities and at the community level. There is a need to address the gaps highlighted with regard to low coverage of PNC services in country. 


\section{Introduction}

The terms "postpartum period" and "postnatal period" are often used interchangeably but sometimes separately, when "postpartum" refers to issues pertaining to the mother and "postnatal" refers to those concerning the baby [1]. In this report, the term postpartum (referring to the period beginning immediately after the birth of the baby and extending up to six weeks or 42 days after birth) is used [2]. The postpartum period is a critical phase in the lives of mothers and newborn babies [3]. Most maternal and infant deaths occur during the postpartum period, yet this is the most neglected period for the coverage and provision of quality care.

For the purposes of describing care provision, the postpartum period consists of immediate, early and late periods [4]. The immediate postpartum period refers to the time just after childbirth, during which the risks to the mother of postpartum hemorrhage and other significant morbidities that are likely to affect the infant such as asphyxia and trauma are highest. The immediate postpartum period covers the first 24 hours from birth. Close direct or indirect supervision by a skilled attendant is required in this period so that any problems can be identified promptly and appropriate intervention can take place [5]. The period from Day 2 through 7 is referred to as the early postnatal period and the period from Day 8 through 42 as the late postnatal period [6].

Globally over 500,000 women die as a result of pregnancy-related conditions. About $60 \%$ of these deaths occur within the first week following childbirth. One million new-born deaths occur within the first 24 hours after birth and $75 \%$ of neonatal deaths occur during the first week of life. Figure 1 shows the timing of maternal and neonatal deaths in days and weeks.

\section{Figure 1: Timing of maternal and neonatal deaths in days and weeks in the postnatal period}

Proportion of maternal death by days postpartum

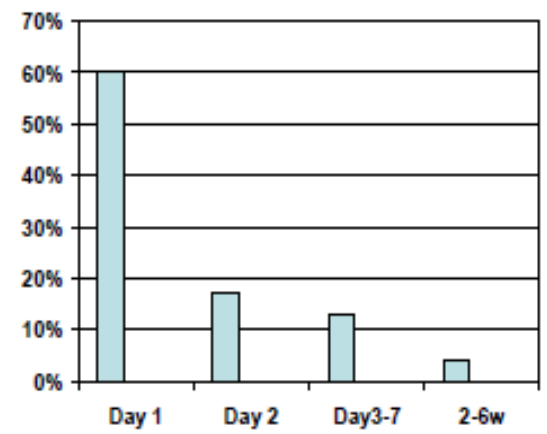

Proportion of neonatal deaths by day

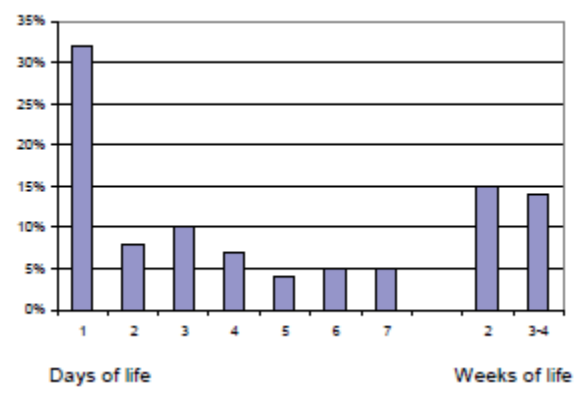

Source: World Health Organization (2010): Technical consultation on postpartum and postnatal care 2010 (Report, WHO/MPS/10.03 -Document No. WHO/MPS/10.03 (2010)). Department of Making Pregnancy Safer; WHO Press, World Health Organization, 20 Avenue Appia, 1211 Geneva 27, Switzerland

Almost two-thirds of infant deaths occur in the first month of life. The situation is similar in Kenya with most maternal and newborn deaths occurring in the early postnatal period. Currently in Kenya, the neonatal mortality rate is contributing to $60 \%$ of infant mortality rate. The risk of dying during postnatal period by day and cause is shown in Appendix 1. 
A large proportion of maternal and neonatal deaths occur during the first 48 hours after delivery. Thus, postnatal care is important for both the mother and the child to treat complications arising from the delivery as well as to provide the mother with important information on how to care for herself and her child. It is recommended that all women receive a check on their health within two days of delivery. To assess the extent of postnatal care utilization, respondents in a national survey were asked whether, for their most recent birth in the five years preceding the survey, they had received a health check after the delivery, and if so, the timing of the first check-up and the type of health provider performing it. This information is presented according to background characteristics in Table 1.

Table 1: Timing of first postnatal check-up

\begin{tabular}{|c|c|c|c|c|c|c|c|c|}
\hline $\begin{array}{l}\text { Background } \\
\text { characteristic }\end{array}$ & $\begin{array}{l}\text { Less than } \\
4 \text { hours }\end{array}$ & $\begin{array}{l}4-23 \\
\text { hours }\end{array}$ & $\begin{array}{l}2 \\
\text { days }\end{array}$ & $\begin{array}{l}3-41 \\
\text { days }\end{array}$ & $\begin{array}{l}\text { Don't } \\
\text { know }\end{array}$ & $\begin{array}{l}\text { No PNC } \\
\text { Check-up }\end{array}$ & Total & $\begin{array}{l}\text { No. of } \\
\text { women }\end{array}$ \\
\hline \multicolumn{9}{|l|}{ Mother's age at birth } \\
\hline$<20$ & 27.8 & 7.9 & 7.7 & 1.9 & 1.0 & 53.8 & 100.0 & 564 \\
\hline $20-34$ & 28.3 & 7.1 & 7.1 & 4.3 & 1.1 & 51.7 & 100.0 & 2,883 \\
\hline $35-49$ & 25.0 & 7.0 & 4.9 & 5.1 & 1.7 & 56.3 & 100.0 & 526 \\
\hline \multicolumn{9}{|l|}{ Education } \\
\hline No education & 18.5 & 6.2 & 2.2 & 5.4 & 0.4 & 67.3 & 100.0 & 441 \\
\hline Primary incomplete & 22.8 & 5.2 & 6.0 & 4.6 & 0.7 & 60.6 & 100.0 & 1,262 \\
\hline Primary complete & 28.0 & 7.8 & 7.6 & 3.2 & 1.3 & 52.1 & 100.0 & 1,225 \\
\hline Secondary+ & 37.5 & 10.1 & 9.2 & 3.9 & 2.0 & 37.3 & 100.0 & 1,045 \\
\hline \multicolumn{9}{|l|}{ Wealth quintile } \\
\hline Lowest & 20.9 & 6.0 & 3.9 & 4.5 & 0.1 & 64.6 & 100.0 & 843 \\
\hline Second & 20.2 & 5.8 & 4.7 & 4.4 & 1.3 & 63.7 & 100.0 & 764 \\
\hline Middle & 25.5 & 7.0 & 6.5 & 4.3 & 0.9 & 55.8 & 100.0 & 742 \\
\hline Fourth & 31.3 & 6.7 & 7.0 & 4.3 & 1.7 & 49.1 & 100.0 & 765 \\
\hline Highest & 40.2 & 11.2 & 12.1 & 3.0 & 2.0 & 31.4 & 100.0 & 859 \\
\hline Total & 27.8 & 7.4 & 6.9 & 4.1 & 1.2 & 52.6 & 100.0 & 3,973 \\
\hline
\end{tabular}

Source: KDHS 2009 (Includes women who received check-up after 41 days)

Table 1 shows that 53 percent of women do not receive postpartum care. Slightly more than one quarter (28 percent) of women receive postpartum care within four hours of delivery, while 7 percent receive care between 4 and 23 hours after delivery. Another 7 percent receive a check-up within two days of delivery, and 4 percent receive care between three and 41 days after delivery. Over $56 \%$ of women deliver at home and hence do not receive a postpartum care visit by trained personnel in a facility especially in the first 48 hours following delivery. Despite the low proportion of women who attend postpartum care clinics, a much higher proportion (91.5\%), do attend antenatal care services.

The KDHS data indicate the need to reach out to rural and poorer women compared to their urban counterparts in Kenya. For instance, only $30 \%$ of rural women compared to $62 \%$ of urban women were seen by skilled providers (doctors, nurses, midwives and clinical officers) during their first postnatal checkup. Similarly, only $18 \%$ of women in the lowest wealth quintile were seen by skilled providers compared to $64 \%$ of women in the highest wealth quintile during their first postnatal checkup. There were wide regional differentials in the proportion of mothers who received postpartum care. For example, in Nairobi Province, 58\% of women received postpartum care within four hours of birth compared to 9\% in North Eastern Province.

Results in Table 2 indicate that 37 percent of women in Kenya receive postnatal care from a medical professional, i.e., a doctor, nurse or midwife. A substantial proportion (10 percent) receives postnatal 
care from traditional birth attendants, and a negligible fraction receives postnatal care from community health workers.

Table 2: Type of provider of first postnatal check-up

\begin{tabular}{|c|c|c|c|c|c|c|c|}
\hline $\begin{array}{l}\text { Background } \\
\text { characteristic }\end{array}$ & $\begin{array}{l}\text { Doctor/ } \\
\text { Nurse/midwife }\end{array}$ & $\mathrm{CHW}$ & TBA & $\begin{array}{l}\text { Other/ } \\
\text { Don't know }\end{array}$ & $\begin{array}{l}\text { No PNC } \\
\text { Check-up }\end{array}$ & Total & $\begin{array}{l}\text { No. of } \\
\text { Women }\end{array}$ \\
\hline \multicolumn{8}{|c|}{ Mother's age at birth } \\
\hline$<20$ & 36.4 & 0.0 & 9.6 & 0.2 & 53.8 & 100.0 & 564 \\
\hline $20-34$ & 37.7 & 0.3 & 10.0 & 0.3 & 51.7 & 100.0 & 2,883 \\
\hline $35-49$ & 32.5 & 0.7 & 10.5 & 0.0 & 56.3 & 100.0 & 526 \\
\hline \multicolumn{8}{|l|}{ Birth order } \\
\hline 1 & 47.3 & 0.0 & 7.9 & 0.5 & 44.3 & 100.0 & 847 \\
\hline $2-3$ & 41.4 & 0.2 & 8.1 & 0.3 & 50.0 & 100.0 & 1,531 \\
\hline $4-5$ & 28.4 & 0.5 & 11.9 & 0.3 & 58.9 & 100.0 & 829 \\
\hline$\overline{6+}$ & 25.1 & 0.5 & $\overline{14.1}$ & 0.0 & 60.2 & 100.0 & 7766 \\
\hline Total & 36.8 & 0.3 & 10.0 & 0.3 & 52.6 & 100.0 & 3,973 \\
\hline \multicolumn{8}{|c|}{ Source: KDHS 2009 (Include\$ women who received check-up after } \\
\hline 41 days) & & & & & & & \\
\hline
\end{tabular}

As seen in Table 2, the birth order is strongly related to type of health provider. Majority of lower parity women received postnatal care from a medical professional. The justification for postpartum care is addressed in the national RH policy of 2007 (See Box 1).

\section{Box 1: Justification for Postpartum Care}

- Providing a continuum of care from ANC, delivery, PNC and beyond results in reduced maternal and neonatal morbidity and mortality.

- It has been estimated that if routine PNC reached $90 \%$ of babies and their mothers, 10 to $27 \%$ of newborn deaths could be averted.

- However 58 \% of women who deliver in Kenya DON'T come for postnatal care.

Source: KDHS 2009 


\section{GOVERNMENT POLICY}

In April 2011, the Government of Kenya published a National Orientation Manual for Health Providers (Nurses, Midwives, Clinical Officers and Medical officers) on targeted postnatal care [7]. A key message emphasized in the manual and other national policy documents such as the Kenya Health Sector Strategic Plan [8] is that postpartum services are implemented as part of the continuum of care services that women need to have access to during pregnancy, delivery and after delivery. In order for postpartum and postnatal services to be meaningful to the mother and to the baby, the visits and services need to be targeted (see Figure 2). Thus, targeted postpartum and postnatal care defines services to be delivered to both the mother and baby in a minimum of four visits spread throughout the first 6 months. Thus, providing a continuum of care during pre-pregnancy, childbirth and after delivery is expected to result in reduced maternal and neonatal morbidity and mortality.

Involving individuals, families and communities in health promotion, emergency preparedness, detection of complications and prompt referral during pregnancy, childbirth and postnatal period will reduce the delays usually experienced and therefore alleviate serious consequences of morbidity and mortality.

Figure 2: Pillars of safe motherhood and the place for targeted postnatal care

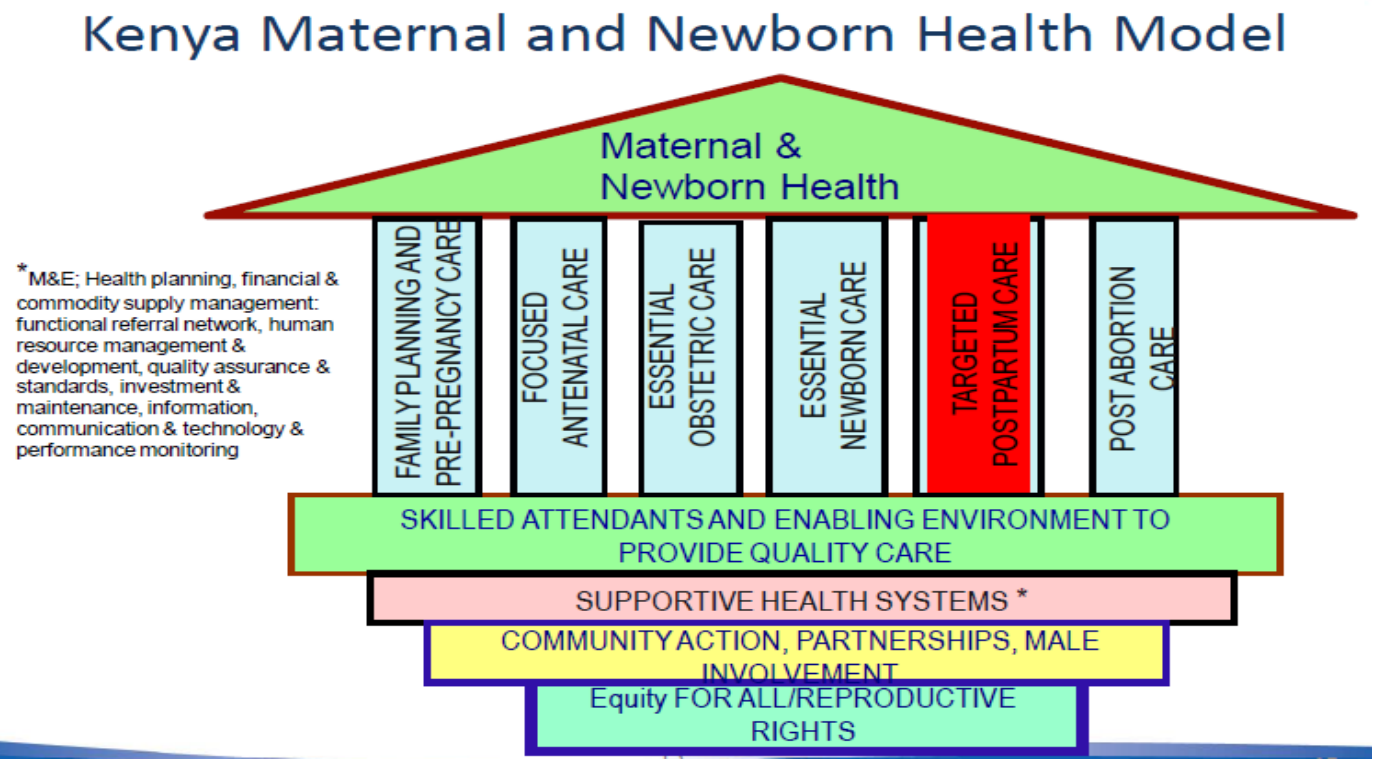

Source: Republic of Kenya (2011): Orientation Manual for Health Providers (Nurses, Midwives, Clinical Officers and Medical officers. Ministry of Health Old Mbagathi Road Nairobi.

A focus on targeted postpartum care is viewed by the policy makers as a strategy for reducing maternal morbidity and mortality. Some of the strategies being employed in Kenya to achieve these goals include the recent declaration of free deliveries in government health facilities. 


\section{TIMING AND FREQUENCY OF POSTNATAL CARE VISITS IN KENYA}

Targeted postnatal care is an approach, which defines a set of postnatal care services delivered to both the mother and baby in a minimum of four visits spread throughout the first six months. These visits are outlined in Box 2.

\section{Box 2: Timing and Frequency of Postnatal care visits in Kenya}

The recommended schedule* for targeted postnatal care in Kenya is as follows:
(a) Within 24-48 hours
(b) Within 1 to 2 weeks
(c) 4 to 6 weeks
(d) 4 to 6 months

*The first assessment should be carried as soon as possible after delivery. If the birth is in a facility the mother and baby should be checked at 1 hour 6 hours and again before discharge. If

\section{CURRENT POSTNATAL CARE PACKAGES OFFERED IN KENYA BY TIMING}

Despite the availability of supportive government policies on postpartum care, in practice the implementation of postpartum activities is fraught with many challenges. For instance, the national roadmap for accelerating the attainment of the MDGs related to maternal and newborn health in Kenya (2010) highlights some of these challenges. Examples include:

- Limited availability and low utilization of skilled attendance during child birth and postpartum period at all levels of the health care system.

- Delay in seeking care in the postnatal period mainly due to negative socio cultural practices such as mother's preference to deliver at home with unskilled attendants.

- Poor integration of postpartum services and HIV/AIDS services as well as with other programs such as immunizations, family planning and adolescent health activities

- Limited participation of communities in MNH matters including postpartum services

- Weak health information system especially for postpartum services. For instance the tools for extracting data or information from the postpartum register are rarely used. Even in situations where information on postpartum services is available, it rarely finds its way to the policy making process or in policy level discussions.

- Weak supportive supervision of community based postpartum services by facility based health care managers. The weak supervision is compounded by lack of standardised monitoring indicators for PPC as part of the national MNH Program

The postnatal care packages offered in Kenya are outlined in Table 3. For purposes of completeness the packages for both the mother and the baby are presented. 
Table 3: Current Postnatal Care Packages offered in Kenya by Timing

\begin{tabular}{|c|c|c|}
\hline Timing & Mother: Provide the following services & Baby: Provide the following services \\
\hline $\begin{array}{l}\text { Within } \\
24 \text { - } 48 \\
\text { hours }\end{array}$ & $\begin{array}{l}\text { - Pain management } \\
\text { - Screening for TB and treat as appropriate } \\
\text { - Vitamin A (200 } 000 \text { i.u.) } \\
\text { - Iron/folic acid supplements } \\
\text { - LLITN } \\
\text { - Treatment or refer in case of any complications } \\
\text { - Appropriate FP method } \\
\text { - If HIV +ve give ARV's for prophylaxis or treatment }\end{array}$ & $\begin{array}{l}\text { - Ensure warmth and put hat on baby } \\
\text { - Delay baby's first bath for the first } 24 \text { hours } \\
\text { - If pre-term encourage skin-to-skin care } \\
\text { - Encourage early initiation of EBF } \\
\text { - Tetracycline eye ointment } 1 \% \\
\text { - Vitamin K } \\
\text { - Immunization (BCG \& birth Polio) } \\
\text { - Infant prophylaxis for HIV as indicated } \\
\text { - Treatment or refer the infant for complications } \\
\text { - Encourage and facilitate birth registration }\end{array}$ \\
\hline $\begin{array}{l}\text { Within } \\
1-2 \\
\text { weeks }\end{array}$ & $\begin{array}{l}\text { - Vitamin A supplementation } \\
\text { - Hematinics } \\
\text { - LLITN (if not yet given) } \\
\text { - Treatment for any complications detected } \\
\text { - Referral as appropriate }\end{array}$ & $\begin{array}{l}\text { - Vitamin A if not yet given } \\
\text { - Immunizations if not yet started } \\
\text { - INH prophylaxis as appropriate } \\
\text { - Treatment of any complications detected } \\
\text { - Referral as appropriate } \\
\text { - Birth registration if not yet done }\end{array}$ \\
\hline $\begin{array}{l}4-6 \\
\text { weeks }\end{array}$ & $\begin{array}{l}\text { - FP method of choice } \\
\text { - CT for HIV } \\
\text { - Screening for cervical cancer } \\
\text { - Clinical breast examination } \\
\text { - Screening for TB \& STI/ RTI } \\
\text { - Treatment for any complications detected } \\
\text { - Referral as appropriate }\end{array}$ & $\begin{array}{l}\text { - Immunizations as per schedule } \\
\text { - INH prophylaxis as appropriate } \\
\text { - Treatment of any complications detected } \\
\text { - Referral as appropriate } \\
\text { - Early infant diagnosis (EID) for HIV } \\
\text { - Management of HIV positive infant } \\
\text { - Birth registration if not yet done }\end{array}$ \\
\hline $\begin{array}{l}4-6 \\
\text { Months }\end{array}$ & $\begin{array}{l}\text { - FP method of choice } \\
\text { - Screening for TB \& STI/ RTI } \\
\text { - Screening for cervical cancer -if not done } \\
\text { - Clinical Breast examination } \\
\text { - CT for HIV } \\
\text { - Treat any complications that are detected } \\
\text { - Refer as appropriate } \\
\text { - Record in PNC register and Mother Child booklet }\end{array}$ & $\begin{array}{l}\text { - Vitamin A supplementation } \\
\text { - Immunizations as per schedule } \\
\text { - INH prophylaxis as appropriate } \\
\text { - Treatment of any complications detected } \\
\text { - Referral as appropriate } \\
\text { - Birth registration if not yet done } \\
\text { - Record in Integrated Register and Mother Child } \\
\text { booklet }\end{array}$ \\
\hline
\end{tabular}

Source: Republic of Kenya (2012): National Guidelines for Quality Obstetrics and Perinatal Care; DRH, MOH, Nairobi, Kenya

\section{PRIORITY HIGH IMPACT INTERVENTIONS BY LEVEL OF CARE AND AGE COHORTS}

Priority high impact Interventions are listed in Appendix 2 by level of care and age cohorts. 


\section{Health System Structures \& Provision of Postnatal Care}

The health system building blocks of the WHO health systems model (summarized in Figure 3) are used in this section to describe the status of postnatal care services in Kenya. The purpose of this approach is to ensure that important aspects of the provision of postnatal care services are assessed as comprehensively as possible. The components assessed are leadership or governance, service delivery, health worker force, information, medical products and financing mechanisms.

Figure 3: WHO Health Systems Framework

Health System Building Blocks

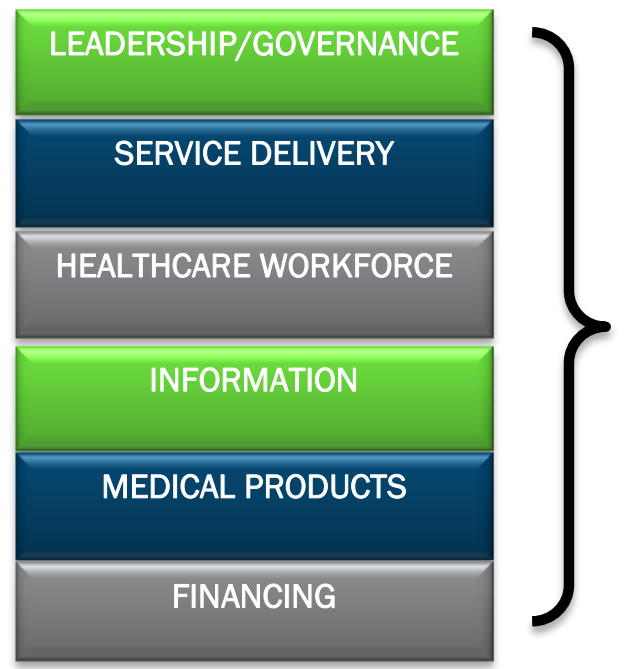

Overall Goals and Outcomes

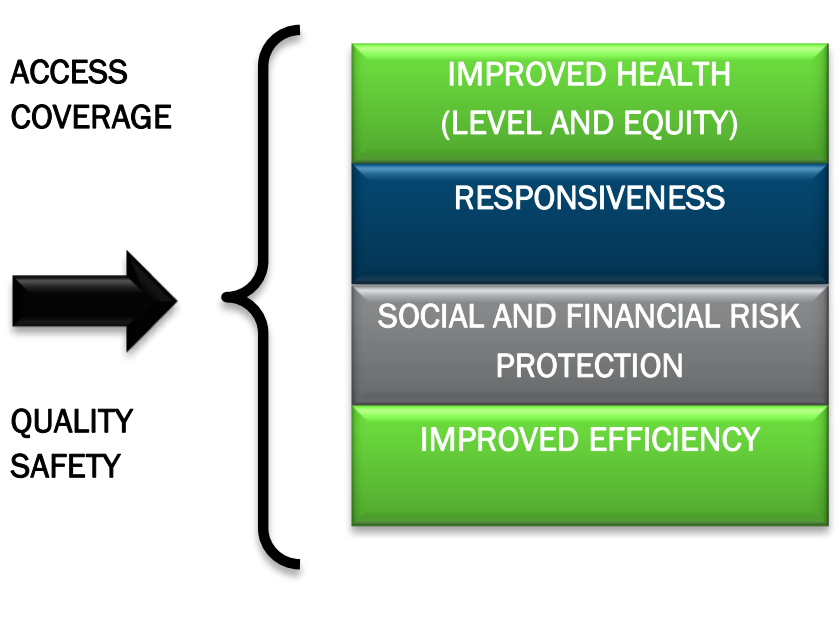

Adapted from WHO 2007 “Everybody business: strengthening health systems to improve health outcomes”: WHO's framework for action. Document Production Services, Geneva, Switzerland.

\section{LEADERSHIP \& GOVERNANCE}

Postnatal care services are part of the Kenya Essential Package for Health (KEPH) [10]. This section describes how postnatal care services are planned, implemented, coordinated, supervised, monitored and evaluated in Kenya.

\section{Planning process}

Planning for health services is done in an integrated fashion in pursuit of long-term national health policy goals. Planning activities respond to the broader policy goal that seeks to make maternal and newborn health services affordable, equitable, accessible and responsive to clients' needs. While planning for health care activities, an attempt is usually made to break down a long-term vision or policy into mediumterm strategic plans, which are in turn developed into annual workplans. Annual workplans may be broken down further into quarterly or monthly activities [11]. Priority actions during planning include:

- Ensuring that all women, including adolescents/youth, have access to reproductive health information, counselling and services; 
- Ensuring that all pregnant women have access to skilled care throughout pregnancy, delivery, postnatal periods and for caring of the new-born;

- Increasing access to both comprehensive and basic emergency obstetric care to meet minimum international standards:

- Removing barriers (geographic, socio-cultural, economic, legal or regulatory) that impede access to skilled care for the poor and 'hard-to-reach' women, including promotion of community midwifery services, women- and baby-friendly services;

- Ensuring that communities are involved in measures to promote 'women-and baby-friendly' maternity services and assisting with transport;

- Ensuring that referral networks across public and non-public facilities are promoted and strengthened;

- Strengthening the capacity of the health system at all levels for efficient and effective delivery of services for the new-born, including resuscitation, thermal regulation, infection prevention and promotion of early and exclusive breastfeeding;

- Strengthening the capacity of community health workers to enable them play designated roles such as promotion of birth-preparedness, early identification and referrals of complications, post-natal care and registration of births; and

- Reviewing all maternal and perinatal deaths and providing notification of maternal deaths.

During planning activities, care is taken to ensure that all key institutions, management teams and individuals in the Kenyan health pyramid [8] are involved. The most basic level of care is at the community level, where services are mainly offered by community health workers (CHWs), community health extension workers (CHEWs) and community midwives. The next level of care is the primary care level - which is the first physical level of the health system, comprising all dispensaries, health centers and maternity as well as nursing homes.

The county level lies in between the national level and the primary care level. The county comprises the first level hospitals whose services complement those provided at the primary health care level. At the top of the health pyramid we have the national level, which besides having tertiary and referral hospitals, is responsible for policy formulation and development of standards and guidelines. For instance, the National Orientation Package for Targeted Postnatal care for Nurses, Midwives, Clinical Officers and Medical Officers referred to earlier was developed by the Division of Reproductive Health in the Ministry of Health.

\section{Implementation}

A successful planning phase is usually followed by implementation of a set of activities that enable mothers and their babies to receive or access particular services within the postnatal phase. During the interaction between a trained provider and the mother and her baby, at the very minimum three activities should take place. These are:

- History taking and checking or performing specific procedures depending on the timing of the consultation. For example, history taking and physical examination will help identify danger signs in the mother during the postnatal period such as high fever, lower abdominal pain and foul-smelling discharge (infection), severe headache, blurred vision, high BP, (pre-eclampsia), convulsions or fits (eclampsia) and heavy vaginal bleeding (PPH). 
- Similarly, history taking and physical examination of the new-born baby will help identify dangers signs in the new-born such as refusal to feed, poor sucking, difficulty breathing, pus and swelling around cord, swollen eyes and convulsions.

- Provision of specific packages of care or services depending on the timing of the consultation. Thus, a woman who has just delivered usually receives different sets of care and advice compared to a woman making a visit to a health facility at six weeks or at six months after delivery.

- Counselling and advice about the mother and the baby. Examples of counselling activities for a mother who makes postnatal visit within 24-48 hours will entail HIV counselling and testing or re-testing and FP counselling (for healthy timing and spacing of pregnancy) and advice on danger signs for mother and baby, personal hygiene and hand hashing, breast care, exercises, care of the perineum, harmful practices, maternal nutrition, use of insecticide-treated nets, cord care and return date.

\section{Coordination and Supervision}

In line with the 2010 constitution, the provision of health services is a devolved function implying that the national government is only responsible for policy making and developing standards and guidelines while the county and sub-county governments are responsible for implementation and dayto-day co-ordination of various activities including postnatal services. Postpartum and postnatal activities are coordinated and supervised as part of the larger reproductive health $(\mathrm{RH})$ and maternal and new-born health $(\mathrm{MNH})$ program. The roles of different institutions in coordinating postnatal activities at all levels are outlined below:

Role of the National Level: The role of the national level is to make appropriate policies and oversee the development of standards and guidelines regarding $\mathrm{MNH}$ activities including post natal services. The national level also ensures that there is adequate capacity in terms of staffing, equipment and supplies for MNH activities including post natal services. The national level also sets standards and regulatory mechanisms including co-ordination of reproductive health training and donor activities.

County and sub-county levels: The county health management teams supervise the planning and implementation of all reproductive health programme activities, including enforcement of reproductive health standards, setting priorities, and collaboration with other partners in $\mathrm{RH}$ and related activities in their respective areas of jurisdiction.

Community level: Through community units, individuals and households are engaged in various health promotion and disease prevention efforts. Members of households, especially women, recognize danger signs and symptoms of conditions that require referral. Community health workers at this level also provide health services and facilitate community diagnosis, management and referral of clients and patients to the next level of care.

The village and the local health facility committees also help in coordinating various health services including resource mobilization for $\mathrm{MNH}$ program activities. Other sectors such as agriculture, social services, education and information, including the mass media, play an important role in advocacy and creation of public awareness on matters related to reproductive health including postnatal services [12]. 


\section{SERVICE DELIVERY}

There is a large discrepancy between what is stated in the policy documents and the actual practice with regard to postpartum or postnatal services. Thus, the policy documents tend to be thorough and detailed in the description of the required services and procedures when compared to the actual practice observed when one visits a health facility or talks to a provider in a health facility.

For instance, the national guidelines on targeted postnatal care address many service delivery components such as definition of service packages, infection prevention and control, quality assurance, referral mechanisms, functional infrastructure and supplies for PPC/PNC. As summarized in Box 3, the views of the Nursing Officer in charge of Kirwara Sub-County Hospital on how postpartum services are run paint a different picture. The hospital is one of the implementing sites of the project on assessing the acceptability of PCVR as a contraceptive among women in Kenya.

\section{Box 3: Implementation of Postnatal activities at Kirwara Sub-District Hospital}

On human resources, the nursing officer said that the main health providers deployed in MCH/FP clinic are nurses (both certificate or enrolled level and diploma or registered level). In case one of the postnatal mothers or her baby has a serious medical condition then such cases are often referred to a clinical officer or a medical officer in outpatient for further assessment and management. She said that her staff usually receive on-the-job training (OJT) on targeted postnatal care and that none of the providers at the hospital has had formal training in postnatal care apart from the content they cover in their basic training as students in nursing colleges.

Regarding the situation of postnatal activities at the community level (within the catchment area of Kirwara Sub-District Hospital), she said that postnatal activities are usually carried out by community health workers (CHWs). She said that some of the messages CHWs communicate to the mothers include:

- The need for mothers to breastfeed their babies exclusively

- $\quad$ Early identification of possible complications during the postpartum period

- How to identify and act on danger signs especially among the neonates

- $\quad$ Feeing of infants

- The need for mothers to take their children for immunization and growth monitoring, and

- Referral as required

CHWs also submit monthly reports to the facilities where $\mathrm{CHWs}$ are attached on various maternal and newborn activities including family planning and postnatal services. The activities which take place at the community level are received and reviewed by the Reproductive Health Coordinator in the Sub-County.

Regarding funding of postnatal activities, she said that postnatal services are not funded separately from other maternal and newborn health activities. Rather, postnatal services are implemented as part of the broader programs that are planned and implemented by the facility itself. On commodities, she mentioned that lifesaving commodities for postnatal care that are available in Kirwara are oxytocin, magnesium sulphate, anti-biotics and anti-hypertensive drugs.

On challenges to improved care, she said there are no physical copies of the national guidelines on targeted postnatal care in the facility and that mothers tend to emphasize the needs of their babies instead of sharing their own concerns with the providers. Other challenges include lack of appreciation on the part of both the providers and mothers of the importance of subsequent visits to the facility, e.g. after two weeks and inadequate or weak recording of the visits.

With regard to integration of services, she said that PNC activities need to be integrated within antenatal care, labor, delivery services, immunization sessions, and growth monitoring sessions as well as care during the pre-conception period. She said that such an approach would lead to greater benefits and improve outcomes for the mother and baby.

In conclusion, she said that integrating PCVR within PNC will be successful only if health providers make an effort and discuss with the mothers using all the opportunities available on the continuum of care 'path' from antenatal care, labour and delivery, and later during family planning and child welfare clinics sessions. 


\section{HEALTH PROVIDERS}

In accordance with the devolved system of government, the Kenya health policy framework provides for four distinct levels or tiers of care:

- Community level: Services at this level are mainly offered by Community Health Workers (CHWs).

- Primary care level: Majority of health providers at this level are nursing officers and clinical officers.

- County level: Majority of health providers at this level are general specialists such as pediatricians, gynecologists, and common cadres such as medical officers, nursing officers and clinical officers.

- National level: Majority of providers at this level provide specialized health care and train both undergraduate and post graduate students.

As shown in Figure 4, most of the doctors are deployed in referral regional and national level hospitals. Majority of the nurses and clinical officers are deployed in county and primary care level hospitals and other health facilities, while community health workers are mainly deployed within communities. Community health workers provide services on a voluntary basis since they are not paid by the government. In some cases CHWs are given a token by the organizations or communities they work for. The numbers in brackets indicate estimates of providers deployed in the public sector.

Figure 4: Distribution of Human Resources for Health in Kenya

Doctors $(1,005)$

Mainly deployed at Levels

4, 5 \& 6

(Referral and County facilities)

Nurses $(22,907)$

Clinical Officers $(2,721)$

Mainly deployed at Levels 2, 3 \& 4

(Primary care and county facilities)

Trained Community Health Workers $(18,038)$

Required Number 250,020

Mainly deployed at Level 1

(Community level)

Adapted from: Accelerating attainment of Health Goals: The Kenya Health Sector Strategic and Investment Plan KHSSP July 2012 - June 2017 Published by: Ministry of Heath 


\section{HEALTH INFORMATION SYSTEM}

Key supervision, monitoring and evaluation tools as well as indicators for assessing availability, accessibility, effectiveness and the quality of postnatal services are outlined in Table 4. Heath information system also addresses issues to do with data collection and transmission, analysis, dissemination, feedback, referral mechanisms and use of PNC reports in a timely manner.

\section{Table 4: Monitoring and Evaluation Tools and indicators}

\begin{tabular}{|c|c|}
\hline \multicolumn{2}{|c|}{ Key Monitoring and Evaluation tools for postnatal services include: } \\
\hline $\begin{array}{l}\text { Mother Child booklet } \\
\text { CHW register } \\
\text { Birth notification forms } \\
\text { Delivery register } \\
\text { Post Natal Register } \\
\text { Family Planning Register }\end{array}$ & $\begin{array}{l}\text { Summary tools } \\
\text { Maternal Death Review Notification Form } \\
\text { Other sources of data } \\
\text { Demographic and Health Survey Report } \\
\text { Health Management Information System } \\
\text { Facility data and summary tools } \\
\text { Community Service Log Book }\end{array}$ \\
\hline Key indicators as required by $\mathrm{MOH}$ for Mother & Key indicators as required by $\mathrm{MOH}$ For the Baby \\
\hline $\begin{array}{l}\text { Percentage of women receiving PPC within } 48 \\
\text { hrs, at } 7 \text { days, and at } 6 \text { weeks after childbirth } \\
\text { Proportion of women who receive three } \\
\text { postnatal checks } \\
\text { Number of maternal deaths within } 48 \text { hrs and } 6 \\
\text { wks after delivery } \\
\text { Proportion of women using FP at } 6 \text { months } \\
\text { postpartum } \\
\text { Number of postpartum women and infants } \\
\text { sleeping under mosquito nets }\end{array}$ & $\begin{array}{l}\text { Proportion of neonatal deaths within } 48 \mathrm{hrs} \text { and } 6 \text { wks } \\
\text { after delivery } \\
\text { Proportion of newborn infants put to the breast within } 1 \\
\text { hour of birth } \\
\text { Proportion of infants exclusively breastfed at } 6 \text { months } \\
\text { Number of HIV exposed newborns tested for HIV at } 6 \\
\text { weeks and at } 3 \text { months } \\
\text { Number of HIV positive mothers on ART } \\
\text { Cases of Ophthalmia Neonatorum } \\
\text { Immunization }\end{array}$ \\
\hline
\end{tabular}

Source: Republic of Kenya (2011): National Orientation Package for Targeted Postnatal care, Division of Reproductive, Health Ministry of Health, Nairobi Kenya

\section{MEDICAL PRODUCTS AND TECHNOLOGIES}

The following key lifesaving commodities are available in Kenya for postnatal care conditions:

- Magnesium sulphate (MgSo4) (for treating eclampsia and pre-eclampsia)

- Misoprostol for preventing and treating postpartum hemorrhage

- Oxytocin, for preventing and treating postpartum hemorrhage

- Chlorhexidine for cord care (for the newborn)

- Injectable antibiotics (for the newborn) and amoxicillin for treating pneumonia

- Resuscitation device for treating newborn asphyxia

- Oral rehydration salts for preventing dehydration from diarrhea

- Zinc for treating diarrhea

NB: plans are underway to include antenatal corticosteroids on the essential drug list.

Other lifesaving commodities available in Kenya for $\mathrm{RH}$ are: Female condoms, contraceptive implants and emergency contraception. 


\section{HEALTH FINANCING SYSTEM}

Availability of adequate financial resources is critical to efficient and effective implementation of health programs including postnatal services at all levels of Kenya's health system. Designing equitable and affordable financing mechanisms that protect poor mothers or households from financial difficulty or impoverishment associated with having to pay for services at the point of use is often a challenge to many households including those seeking postnatal services. The following are sources for financing post natal services:

Government (Treasury Allocations): Some of the postnatal services (such as PMTCT, FP) have strong components of public goods (such as preventive activities, health education) especially for poorer or marginalised clients. As such, government intervention will be critical since private sector health markets have little incentive in providing such goods and services to poorer women. Government financing is also crucial in enhancing the provision of equitable services and in sharing healthcare costs across all populations. In the public sector most of the services provided during the postnatal phase are free of charge at the point of use especially in the primary health care facilities.

Output-based Aid (OBA): Provision of postnatal services could be linked to pro-poor financing strategies such as the Output-based Aid or Approach (OBA). OBA is designed to test the best mechanism of delivering and targeting public subsidies in ways that promote quality care and maximize utilization by the population living in poverty. The OBA concept is based on financing agreed-upon outputs with predefined quality rather than pre-defined inputs by selling vouchers at subsidized prices to clients. In Kenya, postnatal clients could benefit from the safe motherhood voucher.

Other sources: Besides the government funds, other ways of funding postnatal programmes include the following sources:

- External Sources (Support from Development Partners): External funds could support mainly commodities, supplies, training, drugs and technical assistance. External financing may promote allocative efficiency by targeting funds to intended purposes or activities. These resources can also be used in enhancing equity goals.

- Leveraging of Local Development Funds: In recent years, local leaders have used the Constituency Development Fund (CDF) to build various infrastructure, including health facilities. With good justification, it is possible to discuss with relevant officials at the county and sub-county levels with a view to using the funds to support a variety of community-based MNH programs including postnatal services.

- Use of local franchises to fund postnatal services. Examples are PSI's TUNZA ("care") and Marie Stopes Amua ("decide").

- User fees: Those seeking postnatal care in private sector health facilities either pay out of pocket or through insurance. 


\section{Integration of Key RH \& PHC services into Postnatal Care Activities}

In 2009, the Government of Kenya published the National Reproductive Health (RH) and HIV and AIDS Integration Strategy [13]. The strategy provides guidance on restructuring and reorienting health systems to ensure the delivery of HIV and AIDS services within the same sexual and reproductive health (SRH) services or delivery of SRH services within HIV and AIDS services, during the same hours. The strategy identifies priority activities for major implementers of RH and HIV and AIDS programmes to provide sustainable integrated RH and HIV and AIDS services. The strategy elaborates on the relevant provisions in the 2007 Kenya Reproductive Health Policy [14], Kenya National AIDS Strategic Plan III 2005-2010 and National Health Sector Strategic Plan II 2005-2010.

Key reproductive health and primary health care services that are being integrated into postnatal services are: Post-partum family planning services, immunization activities, prevention of Mother to Child Transmission of HIV (PMTCT), counselling and testing for HIV, screening for tuberculosis and referral of clients in the post-partum period, management of post-partum psychotic disorders, promotion of maternal nutrition activities, sexually transmitted infections, conducting physical examination on mothers and their babies for danger signs, strengthening breast feeding and infant nutrition practices and gender-based violence services (Figure 5). Each of the above components is reviewed regarding the extent to which these services have been integrated with postpartum services, current gaps and coverage of the target population.

Strengthening post-partum family planning services: Postpartum FP (PPFP) is the initiation and use of FP methods during the first year after delivery. FP unmet need is high among women during the first year after childbirth. Postpartum contraceptive programmes are convenient, cost-effective and meet the needs of women. This report focuses on the use of postpartum intrauterine contraceptive device (PPIUCD), which has been demonstrated to be safe and effective. ${ }^{1}$ In 2008 , the World Health Organization Medical Eligibility modified its classification of the PPIUCD as a Category One contraceptive method during the first 48 hours postpartum, meaning there is no restriction for the use of this contraceptive method.

The timing for inserting PPIUCD may be as follows:

- Post-placental -within 10 minutes after placenta delivery

- Immediate postpartum - delivery to 1 week

- Postpartum -1 week up to 6 weeks

- Extended postpartum -6 weeks to one year after delivery. Integrating information and messages on FP services into post natal care is an important strategy for reaching vulnerable women who are likely to become pregnant. Providers are required to counsel women on all suitable methods including when to initiate FP methods based on breastfeeding status, timing of visit and an option for referral.

\footnotetext{
1 World Health Organization. Medical Eligibility Criteria for Contraceptive Use 2008 Update. Geneva.
} 
The commonly used techniques for PPIUCD insertions are hand (manual) and forceps (instrumental) either vaginally or through cesarean section. Manual insertion can only be conducted within ten minutes after delivery of placenta, and instrumental insertion can be conducted within ten minutes after delivery of placenta or after ten minutes to 48 hours post-delivery 2 .

Studies on postpartum family planning in Kenya are limited. Results of one of the pilot studies that sought to test the feasibility of introducing postpartum intrauterine contraceptive device (PPIUCD) in Eastern Province of Kenya show mixed results. For instance, results from an FP-Access study that sought to assess women's experience with regard to PPIUCD insertions and to learn about service providers' perspectives, practices and experience with PPIUCD services [15] show that although in July and August 2010 the evaluation team had intended to reach all the 123 service providers who were trained on PPIUCD in Embu County since 2007, only 40\% (49 out of 123) of them were traced.

At the time of interview, only $29 \%$ of the service providers (14 out of 49 ) reported conducting IUCD insertions in the past month (prior to the interview). Among these 14 service providers, a total of 68 insertions were recorded in a one-month period. Most of the insertions were interval at $66 \%$ (45 out of 68 ), followed by post placental at $22 \%$ (15 out of 68 ) and immediate postpartum at $12 \%$ (8 out of 68 ) insertions.

Given the high number of health providers who were reported to have been transferred to other departments or to other health facilities, it is probable that that those who couldn't be traced (74 out of 123) might have faced the same challenge. Some service providers also mentioned some negative experience with PPIUCD insertions ${ }^{3}$. These included:

- Rumors and/or myth about IUCD;

- Excessive bleeding after the insertion;

- Clients changed mind

Integrating immunization activities: Integrating family planning (FP) and immunization services presents a unique opportunity to reach out to majority of the targeted postpartum women. A recent study of 5 countries in sub-Saharan Africa suggests that reaching postpartum women through immunization contacts could decrease overall unmet need for FP by up to $8.9 \%$ [16]. An estimated $80 \%$ of women will visit a healthcare facility to get their infants immunized in the first year following childbirth.

A review of the Maternal and Child Health Integrated Program [MCHIP] that reports on scaling up six high-impact interventions [16] shows mixed results with regard to the integration of immunization and post-partum services in Kenya. Under the auspices of the MCHIP new and underutilized vaccine introduction [NUVI] program, pneumococcal conjugate vaccine [PCV] was introduced to prevent meningitis and pneumonia. Results of the evaluation exercise undertaken in 2013 show that the three countries [Kenya, Malawi and Tanzania) achieved a coverage of $80 \%$ to $90 \%$ of eligible children fully vaccinated with PCV through routine immunization system. Although the immunization activities for NUVI/PCV were fully integrated within postnatal services, the fact that the bulk of the funds for the exercise were provided by UNICEF, WHO and GAVI (and not host countries) raises valid questions about the sustainability of the program.

\footnotetext{
2 Elaine Charurat et al. 2011. "An Assessment of Postpartum Intrauterine Contraceptive Device Services in Embu, Kenya." Access USAID (Family Planning Initiative).

3 ibid.
} 
Prevention of Mother to Child Transmission of HIV (PMTCT): If the mother is HIV positive, ARV's are given for prophylaxis or treatment. According to the national PNC guidelines, key messages for the mother are related to dual protection, infant feeding and maternal nutrition, early infant diagnosis, adherence and family planning. In October 2010, MCHIP began working closely with the $\mathrm{MOH}$ to improve the quality and uptake of PMTCT Services [17] in a demonstration project in Bondo District, Kenya. Evaluation of the project in 2012 showed marked improvements. For instance, the proportion of HIV-exposed infants tested at 6 weeks had increased from 27\% in 2010 to $78 \%$ in 2012. Despite this success, national scale-up of programme activities has been a challenge mainly due to capacity issues and increased demand for services by the population. Two main challenges in this pilot programme have been the high monthly stipends paid to community health volunteers (CHVs) amounting to $\$ 100,000$ per year and the inability of the program to carry out longitudinal follow up of cohorts of clients since Kenya uses cross-sectional registers [17].

Counselling and testing (C\&T) for HIV: Every woman and her partner should be offered HIV testing during their pregnancy and postpartum period especially if she wasn't tested within a period of 3 months preceding the visit. C\&T for HIV is a critical procedure for preventing mother- to-child transmission of HIV since it helps in identifying women early enough for them to benefit from interventions. HIV-infected mothers are counselled on prophylaxis and treatment. Those who test negative are counselled on how to remain negative and lead healthy lives.

Findings from a rapid results initiative (RRI) undertaken by the Ministry of Health in 40 health facilities in Kenya to link HIV services with services provided at $\mathrm{MCH}$ clinics show that five out of the seven indicators which were tracked surpassed the national target [18]. The indicators sought to measure counselling and testing, provision of antiretroviral therapy (ART) services, early infant diagnosis and comprehensiveness of postpartum as well as post-natal services. Although the project succeeded in institutionalizing $\mathrm{MCH}$ clinics as a one-stop-shop for RH and HIV services, it isn't clear from the report whether these services have been scaled-up beyond the 40 pilot clinics.

Screening for tuberculosis (TB) and referral of clients: According to the national PNC guidelines, the reasons for integrating TB into PNC services are:

- TB is one of the leading infectious causes of death among women of reproductive age

- $\quad$ PPC clients are eligible for TB screening according to the national TB/HIV guidelines

- Children born to smear-positive mothers are at high risk of TB infection.

- All mothers visit health facilities for their babies' immunization and growth monitoring, and this offers an opportunity for TB screening and management.

Despite the fact that TB is one of the leading causes of the high burden of disease, many providers do not routinely screen postpartum clients to identify the condition [19]. In a published study that examined the feasibility and effects of screening and referral for tuberculosis within postpartum settings, 14 out of 12,604 (approximately 11 per 10,000) postpartum women were diagnosed with tuberculosis. Although the study concluded that postnatal/postpartum services provide useful platforms for TB screening and detection as provided for in the national guidelines, the approach hasn't been institutionalized. Hence the need for more resources and policy-level support to create awareness at all levels of the health care system given that Kenya has one of the world's highest TB disease burdens ${ }^{4}$.

\footnotetext{
4 World Health Organization (2013): Global tuberculosis report 2013. World Health Organization, 20 Avenue Appia, 1211 Geneva 27, Switzerland
} 
Management of postpartum mental disorders: The national PNC guidelines state that postpartum emotional distress is common after pregnancy and ranges from mild postpartum blues to postpartum depression or psychosis. Postpartum psychosis can pose a threat to the life of the mother or baby, and therefore the postpartum period should be considered as a vulnerable time for the development of emotional and psychological disorders. Providers are required to screen for signs and symptoms of mental disorders, help clients prevent the problem and provide relief measures.

To date, most of the studies on postpartum depression in Kenya have been undertaken in health facilities. For instance, a 2006 study which examined the magnitude of morbidity among postpartum mothers in Mombasa, Kenya, compared health care needs among those who presented in the early, middle and late postpartum periods [20]. Early postpartum period was defined as four weeks to two months after childbirth; middle postpartum period as two to six months after childbirth while late postpartum period was defined as six to twelve months since childbirth. The study established that the prevalence of depression was about 4\% (18 out of 500) and tended to increase with the duration of the postpartum period (with lower rates at the start compared to higher rates towards the end of the postpartum period). Predisposing factors were low household income, physical and sexual violence and the use of alcohol.

A similar study undertaken at a university teaching hospital in Kenya estimated the prevalence of postpartum depression to be $13.8 \%$ [21]. The author recommended the introduction of regular screening to identify affected mothers to avert the adverse effects that may be associated with the condition. The difference in the prevalence rate could be attributed to variations in the locations where the clients were recruited. In the Mombasa study, mothers were recruited at the immunization clinic, while mothers in the Aga-Khan study were recruited at the postpartum clinic.

Promotion of maternal nutrition activities: Maternal nutrition is an important aspect of postnatal care. Following a normal delivery a woman may be hungry and should have access to food. Providers should work with facility mangers to ensure that maternity units have food for women who deliver including those who do so at night. On discharge, mothers should be counselled on taking an extra meal and snacks rich in protein and micronutrients. Health providers need to integrate information on energy and protein requirements during lactation in other post natal messages.

Adequate micronutrient intake by pregnant or lactating women has important health benefits for women and their babies. According to the Kenya Demographic and Health Survey (KDHS) of 2008/2009, 46\% of women received a dose of vitamin A postpartum (a significant increase from 14\% reported in the 2003 KDHS). A much lower proportion (17\%) of women received deworming medication during pregnancy. Most of the activities around maternal nutrition issues have not been evaluated and hence the difficulties of pinpointing specific achievements and gaps.

Sexually transmitted infections (STIs): The national guidelines on integrating STIs/Reproductive Tract Infections (RTIs) into primary health care settings [22] recommend that providers should assess the risk of STIs/RTIs/HIV/AIDS among postnatal clients. For example, providers need to ask about the number of sexual partners, history and current symptoms of STIs/other RTIs (for self and partner), past and present condom use and about client's home life, including partner violence and social support.

Results of a study that assessed the quality of care associated with the integration of STIS/RTIs and HIV into primary health care services [23] show that significant improvements were observed in postpartum care services across all five indicators assessed (Table 5). Virtually all postpartum clients received counselling that included most of the five actions assessed, compared with around one at baseline. 
Table 5: Discussion of STI/RTI issues with postpartum clients

\begin{tabular}{|l|c|c|}
\hline \multirow{2}{*}{ Proportion of consultations in which provider } & \multicolumn{2}{|c|}{ Pooled sample } \\
\cline { 2 - 3 } & Baseline $(\mathrm{n}=98)$ & Endline $(\mathrm{n}=163)$ \\
\hline Discussed risks e.g. History of symptoms of STIs/RTIs & 11 & $71^{\star *}$ \\
\hline Looked for signs \& symptoms of STIs/RTIs e.g. discharge & 32 & $66^{* *}$ \\
\hline Screened for signs of infection following delivery & 49 & $89^{* *}$ \\
\hline Discussed prevention of STIs/RTIs (including HIV) & 21 & $54^{* *}$ \\
\hline Promoted male and female condom use & 7 & $47^{* *}$ \\
\hline Total Score (0-5) & 1.2 & $3.27^{*}$ \\
\hline
\end{tabular}

** Significant at $p<0.01 ;$ * Significant at $p<0.05$.

Source: Liambila W., Mullick S., Askew I., Broutet N., Mohammed I., Awuor C., Kigen B., Mutunga C. et al. 2010. Introducing and Pilot-testing the National Guidelines on Integrating the Management of STIs/RTIs into RH Settings in Kenya; Population Council: Nairobi, Kenya

Although the project succeeded in demonstrating the feasibility of integrating STIs/RTIs in primary health care settings including postpartum clinics, recent evidence regarding the status of these activities, and in particular whether these services have been scaled-up beyond the pilot phase, isn't available.

Conducting physical examination of mothers and their babies: Emergency preparedness and complication readiness for the mother and baby saves many lives [24]. Early detection and treatment of problems such as eclampsia, hemorrhage, infections and unsafe abortion for mothers and newbornasphyxia, neonatal sepsis, low birth weight and intra-partum stillbirth for babies are critical in ensuring their survival. However, despite the availability of elaborate guidelines, in practice many mothers seeking postpartum services do not benefit from routine physical examination due to a number of barriers. Examples include lack of updates on the revised PNC/PPC guidelines ${ }^{5}$, negative provider attitude towards postpartum services and shortage of providers in health facilities ${ }^{6}$.

Strengthening breast feeding and infant nutrition practices: It is important that information and messages on breast feeding and infant nutrition practices are integrated within the postnatal care activities. Providers should ensure that a mother is in a comfortable position while breastfeeding. Providers also need to train mothers on how to feed the baby and on signs of effective suckling. The following information should be discussed with the mother:

- The importance of exclusive breastfeeding for the first 6 months unless medically contraindicated e.g. a mother who is HIV positive who chooses not to breastfeed

- The need to avoid giving the baby water or any other food or fluid in the first 6 months

- The importance of breastfeeding in the delivery room. Mothers undergoing Caesarean Section should be assisted to put baby to breast as soon as they are awake

- Informed feeding choices for HIV-infected mothers

- How to maintain lactation if separated from their babies, e.g. by expressing breast milk and keeping it in clean covered cups. Providers need to remind mothers that expressed breast milk can remain for 8 hours at room temperature.

\footnotetext{
5 Repositioning Postpartum Care in Kenya Safe Motherhood Policy Alert, April 2005,Population Council

6 Violet Naanyu et al (2011): Exploring Low Uptake of Skilled Delivery Services and Postpartum Family Planning Services among Women Living in Western Kenya; Measure Evaluation, PRH Working Paper Series, WP-11-117, Carolina Population Center, Chapel Hill, NC 27516;
} 
A review of data on breast feeding and infant nutrition practices from the 2008/09 Kenya Demographic Health Survey [25] shows that:

- Early initiation of breastfeeding is encouraged. Thus 58\% of children are breastfed within one hour of birth and 86 percent within one day after delivery. The median duration for any breastfeeding among Kenyan children is 21 months. The median duration of exclusive breastfeeding is less than one month, though the mean duration is 3 months.

- Complementary feeding practices are common in Kenya. By the age of 4-5 months, three in ten breastfed children are also fed solid or semi-solid foods. Use of infant formula milk and fortified baby foods is minimal. Only 3 percent of children under three years old receive commercially produced infant formula.

- Only 39\% of all children age 6-23 months are fed in accordance with all infant and young child feeding (IYCF) practices.

- About 30\% of children ages 6-59 months were given vitamin A supplements in the six months before the survey. Children aged 9-11 months were most likely to have received vitamin A supplements (60 percent). Survey data on iron supplementation indicate it is generally low (at 5 percent).

The KDHS data emphasize the need to integrate information and education activities about breast feeding and infant nutrition practices within postpartum and postnatal services.

Screening for gender-based violence services: A recent Kenya Demographic and Health Report [25] showed that $39 \%$ of women have experienced physical violence, with almost one in four women (24\%) experiencing such violence in the 12 months before the survey. Preliminary results of a recent study in Kenya suggest that gender-based violence is common in the postpartum period [26]. About $20 \%$ of the women in the study reported that their partner said or did something humiliating or threatening to hurt her. Figure 5 provides a summary of the integration activities.

Figure 5: Integrating key reproductive and primary health care services into postnatal care activities

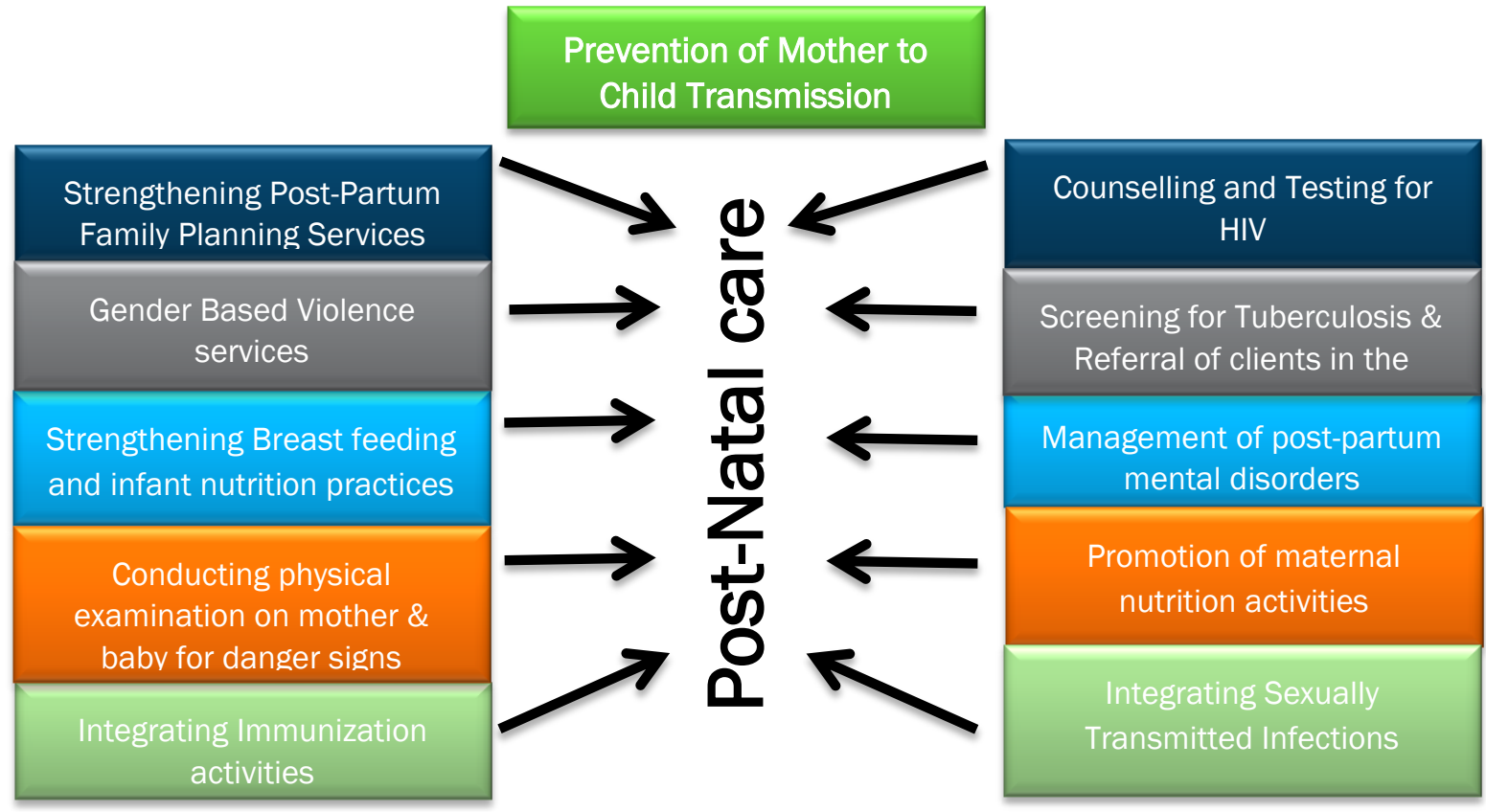




\section{Highlights of Best Practices in Postnatal Care}

This section presents highlights of best practices in postpartum care. Only those practices which were piloted and the results of which as well as the lessons learned were used in developing, revising or updating the national Ministry of Health $\mathrm{MOH}$ guidelines are considered. Using these criteria, five examples are highlighted:

- Experiences with the Post-Partum Intrauterine Contraceptive Device (PPIUCD) in Eastern Province, Kenya

- Using community midwives to provide postnatal and postpartum care

- Best Practices from the MCHIP/Kenya Program Experiences

- Integrating STIs/RTIs into Postnatal care

- Feasibility and effect of integrating tuberculosis (TB) screening and detection in postnatal care (PNC) and postpartum care (PPC) services

\section{EXPERIENCES WITH THE POST-PARTUM INTRAUTERINE CONTRACEPTIVE DEVICE (PPIUCD)}

The postpartum period is considered to be important not only by the Ministry of Health but also by key players who are involved in supporting the provision of various products and services that are appropriate and relevant during the post-partum period. With regard to family planning services, evidence from the Kenya Demographic and Health services shows that women in the postpartum period face many challenges, including a larger unmet need for FP compared to the other target groups of women [27].Therefore introducing suitable methods during the postpartum period such as PPIUCD increases the available FP method-mix. In 2008, the World Health Organization modified the medical eligibility criteria for PPIUCD and re-classified it as a Category One contraceptive method during the first 48 hours postpartum, meaning there is no restriction for the use of this contraceptive method. Following this milestone, guidelines were developed by WHO, but at country level operational experience on how to implement them was lacking. This best practice demonstrates how the partnership between Jhpiego, Population Council and the Ministry of Health led to the design, implementation and evaluation of the project on the use of post-partum intrauterine contraceptive device (PPIUCD). 


\section{Box 4: Experiences from the Pilot Project on the use of PPIUCD}

Nearly half of mothers in Kenya access postpartum care by 6 weeks after delivery. Thus, the immediate postpartum period is a great opportunity to engage mothers on family planning (FP) to address the high unmet need for contraception in Kenya that is currently estimated at $26 \%$. The PPIUCD, an effective, long-term method, expands method choice in the single setting of delivery and contraception. Between 2007 and 2010 a PPIUCD pilot project was implemented at the Embu Provincial General Hospital (EPGH) and subsequently scaled to District hospitals and health centers in Eastern province. The evaluation was undertaken from July to November 2009.

The approach followed involved advocacy activities with the Provincial Health Management Team (PHMT) around postpartum long-term family planning methods. Piloting of the PPIUCD was done at EPGH. Capacity-building for trainers and service providers (SPS), including community health workers (CHWs) was conducted. PPIUCD was integrated into pertinent services and wards. Adequate supplies and equipment were provided, and client access to a PPIUCD service provider was assured on a round-the-clock basis, along with access (for service providers) to a mentor for continuous on-the-job training. Client exit interviews were conducted with PPIUCD acceptors, in addition to interviews with service providers on their experiences with offering the PPIUCD and suggestions/recommendations.

In terms of results, great satisfaction was reported by $99 \%$ of clients. SPs recommended that PPIUCD counseling form part of focused antenatal care, citing various positive aspects of the PPIUCD, including ease of insertion and cost effectiveness for clients, SPs, and the institution. Subsequent scale-up occurred in 25 facilities, including 4 district hospitals and 22 health centers. Five of the trained SPS became PPIUCD champions, providing additional mentorship to facilities that newly offered PPIUCD, and becoming provincial and national advocates for the method. During the period 2007-2010, a total of 936 PPIUCD insertions were done as follows: Post placental 615 (66\%); immediate 224 (24\%); and transcaesarean 94 (10\%). Only one PPIUCD expulsion was noted.

In conclusion- the immediate postpartum period offers an opportunity to provide long-term contraception, such as PPIUCD. Advocacy and sensitization of key stakeholders, community mobilization, and ease of access to the method and to mentors are all useful in ensuring the uptake of the PPIUCD. In a June 2014 report by Jhpiego [16] on lessons learned from the six high impact interventions in Reproductive, Maternal, Newborn, and Child Health (RMNCH), the authors point out that there hasn't been any population level impact evaluation of the PPUICD mainly because of the small number of acceptors.

Source: Ruth K. Jahonga, Kenneth Chebet and Nancy Koskei (2011): Experiences with the Post-Partum Intrauterine Contraceptive Device (PPIUCD) in Eastern Province, Kenya; Jhpiego, Kenya-Presentation made at the International FP Conference in Senegal.

\section{POSTPARTUM PRACTICES IN COMMUNITY MIDWIFERY}

Majority of women in Kenya (over 56\%) deliver at home and many of them experience a number of obstetric complications at the community level. In order to increase the proportion of deliveries conducted by skilled attendants at the community level and address some of the common obstetric and perinatal morbidities at this level, the Ministry of Health in collaboration with Population Council launched the community midwifery model. The model is an innovation which involves the engagement of skilled midwives residing in communities to take critical maternal health services to women's homes, thus improving maternal, newborn and infant health [28]. The postpartum practices highlighted in this section are based on a study that aimed to assess the effect of expanding community midwives' mandate to go beyond the provision of delivery services alone, to incorporate a more comprehensive package of reproductive health such as antenatal care, postpartum care, and family planning and HIV services. The operations research project involved pre- and post-intervention data collection without a comparison group to assess intervention effects. The project was implemented in the Bungoma and Lugari Districts of Western Province, Kenya. A review of findings on the postpartum component in Table 5 shows that the expanded community midwifery model improved clients' access to various services including family planning. The proportion of postpartum clients together with their babies who were checked by CMs within 48 hours increased significantly from $52 \%$ 
at baseline to $67 \%$ at endline. There were also significant improvements in the proportion of clients who started using contraceptive implants since their last delivery.

Table 5: Distribution of women by place, timing and QOC received at postpartum check-up (\%)

\begin{tabular}{|c|l|l|l|}
\hline & \multicolumn{1}{|c|}{$\begin{array}{c}\text { Baseline } \\
(\%)\end{array}$} & $\begin{array}{c}\text { End line } \\
(\%)\end{array}$ & $\begin{array}{c}\mathrm{p}- \\
\text { value }\end{array}$ \\
\hline Place where first check up after delivery took place & $(\mathrm{N}=245)$ & $(\mathrm{N}=262)$ & \\
\hline Own home with CM & 42 & $25^{* *}$ & 0.000 \\
\hline CM's home & 33 & $50 * *$ & 0.000 \\
\hline Health facility & 20 & 24 & 0.277 \\
\hline TBAs home & 2 & $0^{*}$ & 0.021 \\
\hline Others (specify) & 2 & 1 & 0.351 \\
\hline Timing for first check-up by community midwife for mother and baby & $(\mathrm{N}=225)$ & $(\mathrm{N}=212)$ & \\
\hline Within 48 hours & 52 & $67^{* *}$ & 0.001 \\
\hline Between 3 - 6 days & 23 & $13^{* *}$ & 0.006 \\
\hline Between 1 - 2 weeks & 15 & 16 & 0.772 \\
\hline Between 3 - 6 weeks & 8 & 4 & 0.079 \\
\hline More than 6 weeks & 1 & 0 & 0.144 \\
\hline Proportion of clients who discussed FP Methods of their choice with CM & 64 & 69 & 0.268 \\
\hline Proportion of clients given information on how to care for the baby by CM & 77 & 81 & 0.305 \\
\hline Proportion of clients who were given information on cord care by a CM & 83 & 87 & 0.242 \\
\hline $\begin{array}{l}\text { Proportion of clients who had started using a implants since their last } \\
\text { delivery }\end{array}$ & $5(\mathrm{~N}=128)$ & $\begin{array}{l}21^{* *} \\
(\mathrm{~N}=136)\end{array}$ & 0.000 \\
\hline Proportion of clients who had started using IUCD since their last delivery & 2 & 4 & 0.343 \\
\hline
\end{tabular}

Significant at $* p<0.05 ; * * p<0.01$. CM: Community Midwife; TBA: Traditional birth attendant.

Source: Wilson Liambila, Francis Obare, Chi-Chi Undie, Harriet Birungi, Shiphrah Njeri Kuria, Ruth Wayua Muia and Assumpta Matekwa (2013): The community midwifery model in Kenya: Expanding access to comprehensive reproductive health services at the community level: AFRICAN Journal of Midwifery and Women's Health, Oct.-Dec. 2013, Vol 7, No 4

\section{MCHIP KENYA PROGRAM EXPERIENCES}

In 2009 the Division of Family Health (DFH) under the Ministry of Health (MOH) made a request to USAID for support to strengthen its mandate for national coordination and technical guidance in $\mathrm{MNH}$ activities. As a result, the MCHIP program was engaged to assist the DFH, and its divisions, to provide management, coordination, and technical leadership in maternal, newborn, and child health (MNCH) across the country. Since 2009, MCHIP has built the management, supervision, information technology, monitoring and evaluation (M\&E), institutional, and technical capacity of the divisions and strengthened the DFH's overall capacity to lead effective health programs countrywide. An element of technical leadership has also included supporting the DFH to demonstrate innovations and highimpact interventions in $\mathrm{MNCH}$ and develop strategies for scale-up. These demonstrations were implemented in selected districts of Bondo, Igembe North, and East Pokot. Some of the projects are highlighted in Box 5 as best practices. 


\section{Box 5: Best Practices from the MCHIP}

Maternal, infant and young child nutrition (MIYCN) guidelines MCHIP supported the finalization of the MIYCN Operational Guidelines for Health Workers enabling the operationalization of the National MIYCN policy and strategic plan. Using these comprehensive guidelines, the MCHIP/Kenya team supported the Division of Nutrition (DON) and the AIDS, Population and Health Integrated Assistance (APHIA-plus) health programs to strengthen community-level support for MIYCN interventions by building the capacity of health workers and community health workers (CHWs) in MCHIP demonstration districts (Igembe North and East Pokot) as well as nationally in most of the counties. Dissemination of the guidelines is ongoing in most of Kenya's 47 counties.

Baby-friendly community initiative Since 2010, MCHIP Kenya has been working closely with the DON to promote breastfeeding and complementary feeding by developing the Baby-Friendly Community Initiative (BFCl), which complements the Baby-Friendly Hospital Initiative. To begin, MCHIP conducted a two-province assessment of BFCl activities, identifying key intervention opportunities. A BFCl monitoring and assessment tool was developed in close collaboration with the DON in preparation for new community-focused activities to promote MIYCN. Orientations were conducted on how to use the tools to conduct facility self-assessment, supportive supervision, and for $\mathrm{CHWs}$ to conduct follow-up and referrals to health facilities. Following national dissemination supported by MCHIP to all counties, many facilities are now using the tool, and one facility and community has been assessed and accredited as baby friendly.

Community support group engagement The MCHIP/Kenya team has engaged with more than 25 community support groups in Bondo and Igembe North that meet at least once monthly. The majority of participants are mothers, expectant mothers and grandmothers (with some participation from husbands). The MCHIP nutrition team is utilizing these groups to integrate key HINI's, such as: exclusive breastfeeding; complementary feeding; water, sanitation and hygiene; growth monitoring and promotion; vitamin A supplementation; IFA supplementation; and diarrheal disease management. Additionally, the team, in collaboration with the Ministry of Agriculture (MOA) and 25 community support groups in lgembe North, is promoting the use of local ingredients to enhance the nutritional content of complementary foods provided by mothers to their children beginning at six months of age. To reach this end, MOA representatives and mothers convene to share and discuss ingredients used to prepare meals for young children. This documentation process will result in the creation of a standardized recipe brochure for use at the community level.

\section{INTEGRATING STIS/RTIS INTO POSTPARTUM CARE}

\section{Sexually transmitted and other reproductive tract infections (STIS/RTIs) present a major burden of} disease in Kenya and are responsible for high levels of maternal and infant morbidity and mortality. In order to address the high prevalence of STIs/RTIs globally, WHO and its partners, Population Council and Family Health International, developed guidelines for integrating these services into other sexual and reproductive health services in primary health care settings. These guidelines were adapted locally and the Kenyan teams produced the Kenya National Guidelines on the Integration of Services for Reproductive Tract Infections (RTIs), which were launched in June 2006.

The adapted guidelines were then introduced and evaluated in ten health facilities in Kenya (five in Kilifi District in Coast Province and five in Meru South District in Eastern Province). The interventions used in introducing the guidelines included revision of the original training materials and job aides, training of health providers, modification of $\mathrm{MOH}$ registers, strengthening commodity logistics, enhancing supportive supervision, and regular monitoring [29]. Data for the evaluation were collected through observations of provider-client interactions (382 at baseline and 743 at endline), client exit interviews (382 at baseline and 737 at endline) and a health facility assessment at each facility.

The results showed that integration into $\mathrm{RH}$ services of activities to screen for and manage STIS/RTIS is feasible, acceptable to clients and providers, and effective in improving the range and quality of 
services offered to clients. Figure 6 shows the results on the quality of counselling on RTI/STI/HIV in postpartum care services. Significant improvements were observed in postpartum care services across all five indicators.

Figure 6: Discussion of STI/RTI issues with postpartum care services.

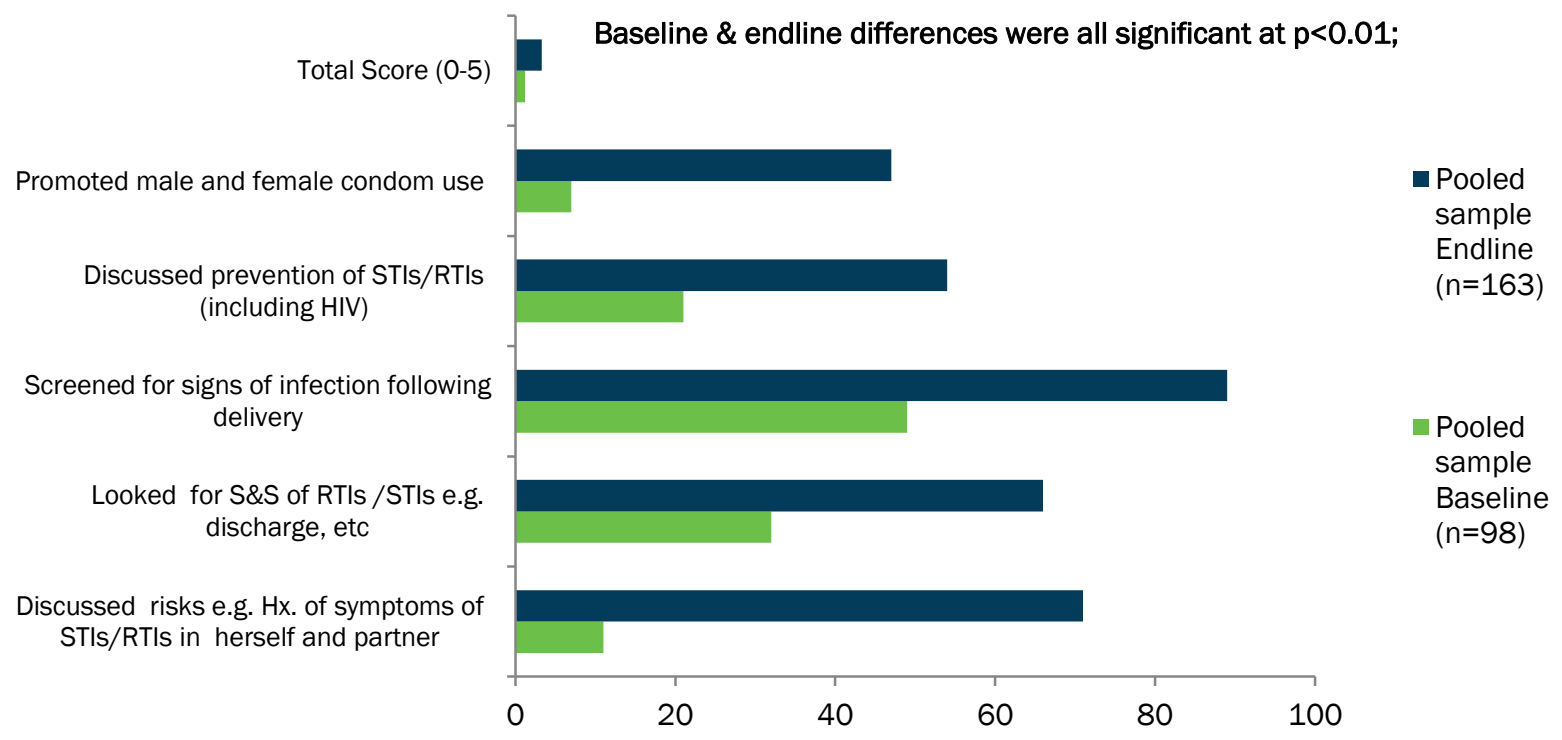

The results shown assisted the Ministry of Health to develop guidelines and procedures for integrating STIs/RTIs into PHC settings including postpartum services shown in Appendix 3.

\section{POTENTIAL FOR THE PROVISION OF PCVR WITHIN POSTNATAL CARE}

Progesterone Contraceptive Vaginal Ring (PCVR) is a new contraceptive method in sub-Saharan Africa. It is designed for use by breast feeding women and can play a key role in increasing access to contraception for millions of women, especially in contexts where majority of women tend to breastfeed their babies for prolonged periods. PCVR is user-controlled and releases $10 \mathrm{mg}$ of natural progesterone per day. It acts by thickening the cervical mucus and inhibiting sperm penetration into the uterus. Effectiveness of $98.5 \%$ has been reported. It is currently registered and sold in Latin America. A study to assess the acceptability of PCVR as a contraceptive among women in sub-Saharan Africa (Kenya, Nigeria and Senegal) is ongoing. Autonomous self-use of PCVR and other vaginal rings is an attractive and important feature of these devices. Furthermore, service providers do not require extensive training on the use of vaginal rings, and most of the focus is on user education and counselling about the ring.

Provision of postpartum family planning in Kenya is a key pillar in the provision of targeted postnatal care. As demonstrated elsewhere [30], PCVR could be distributed by health cadres such as community health workers who do not have sophisticated service provision skills. As a way of sustaining task sharing activities at the community level, both the national and county-level governments in Kenya are promoting the establishment of working partnerships between community midwives and community health workers such that the latter focus on creating community health education, health promotion activities, delivering disease prevention messages, accompanying referred clients, provision of pills 
and condoms to clients; while the former focus on the provision of mainly clinical family planning methods such as IUD and Implants.

Thus PCVR could potentially be dispensed by a range of providers including facility-based midlevel workers such as nurses and clinical officers as well as community health workers who may educate women on how to use this particular method. During the PCVR introductory and sensitization meetings held in April and May 2012 with a number of stakeholders in the family planning sector [20], the civil society groups and the national representatives of women organizations said that women in remote places should be able to access PCVR without any restrictions. In addition, some of the stakeholders said that PCVR should be made available through the public, private, and NGO sectors.

\section{IMPLICATIONS FOR POLICY AND PROGRAMMING}

This section addresses opportunities, challenges and conclusions regarding the available post natal packages in Kenya and the place for PCVR.

\section{Opportunities}

There are many opportunities for facilitating the delivery of Progesterone contraceptive vaginal rings within PNC services in Kenya. First there are many opportunities for integrating post natal services such as promotion of maternal nutrition activities, immunization, strengthening breast feeding and infant nutrition practices and strengthening postpartum FP services. Secondly, the Ministry of Health policy makers view PCVR as a useful product that is meant to widen or broaden the contraceptive options for breastfeeding women in the postpartum period. At the moment health providers only have the progestin-only pill or the mini-pill to offer breastfeeding women.

Thirdly, key audiences in Kenya including the Kenya Obstetrical and Gynecological Society (KOGS) and development partners are aware of the ongoing PCVR acceptability study. Fourth, the policy environment in Kenya is supportive of task-sharing activities. For instance, the national community midwifery guidelines recommend a dual-cadre working approach between community midwives (CMs) and CHWs. Fifth, experiences on the status of PNC activities in health facilities show that despite the lack of a national training strategy some facilities are using OJT (on the job training) as low-cost strategy for imparting knowledge and skills to health providers on PNC.

Sixth, PCVR is perceived to have fewer side effects. Perceived safety of the product and being usercontrolled could increase demand and coverage for PCVR. Seventh, national guidelines and orientation package for PNC and the CHW training curriculum are available at all levels of health care delivery (see Figures 7 and 8). 
Figure 7: Cover image of the national orientation package for post natal care

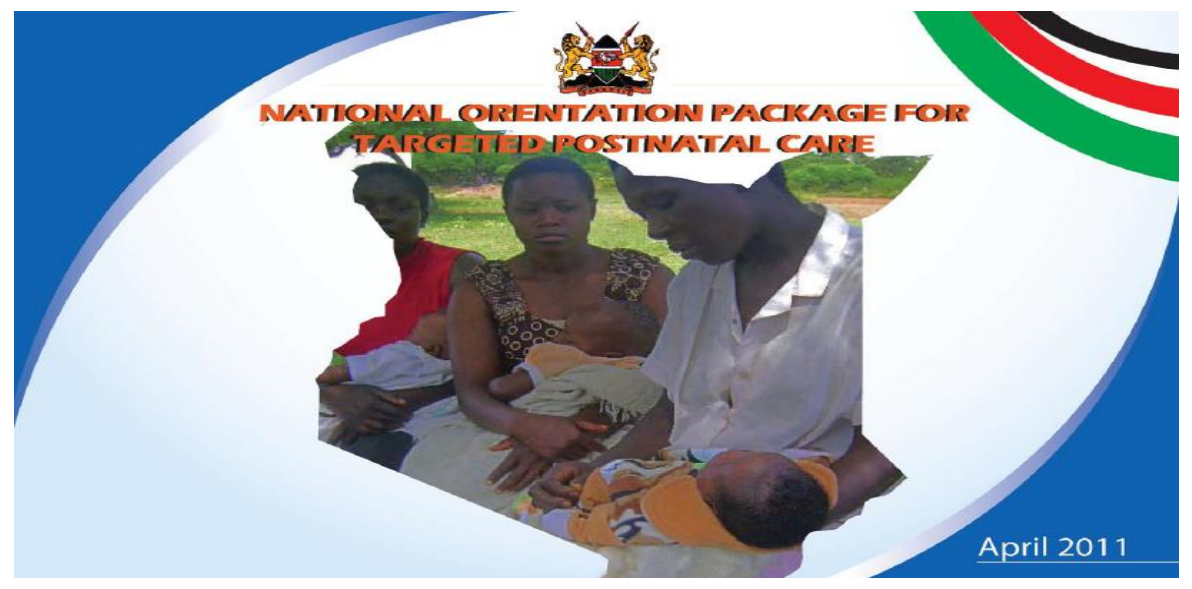

Figure 8: Cover image of the CHW Curriculum and an outline of PNC content

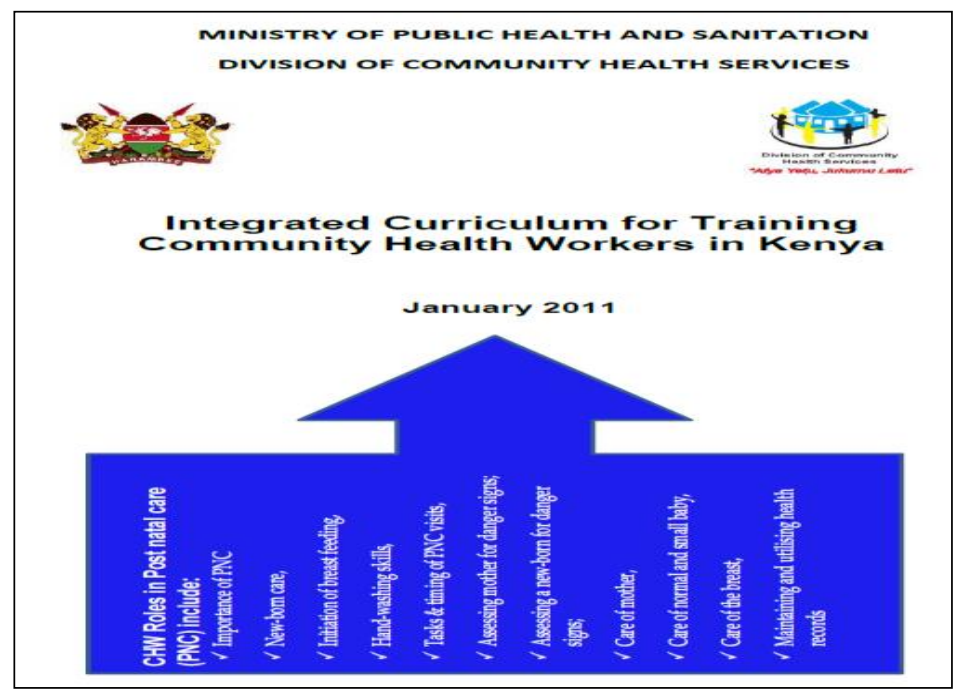

\section{Challenges}

There are a number of challenges to be addressed. First, majority of women in Kenya (over 56\%) still deliver at the community level. Given that about $60 \%$ of the neonatal deaths occur within the first week following childbirth, this means that a substantial proportion of babies and their mothers do not receive quality PNC. Another challenge has to do with inadequate financial resources that are allocated to reproductive health activities. In the context of devolution, county health managers have expressed concern that devolved units aren't prioritizing reproductive health activities including postpartum services. Additional resources will be required to support demand generation activities. 


\section{Conclusion}

The available postnatal care packages provide useful entry points not only for integrating PCVR but also for making it potentially accessible and available in nearly all maternal and newborn points of contact with clients who are in the postnatal phase. The examples highlighted in the area of integration of services as well as those cited under best practices provide major opportunities for scaling up PCVR activities within health facilities and at the community level. There is a need to address the gaps highlighted with regard to low coverage and quality of postpartum services in the country. 


\section{References}

1. World Health Organization (2010): Technical consultation on PPC and PNC -WHO/MPS/10.03, World Health Organization, 20 Avenue Appia, 1211 Geneva 27, Switzerland

2. World Health Organization (2013): Recommendations on Postnatal care of the mother and newborn, October 2013, World Health Organization, 20 Avenue Appia, 1211 Geneva 27, Switzerland

3. Vishnu Khanal, Mandira Adhikari2, Rajendra Karkee, and Tania Gavidia (2014): Factors associated with the utilization of postnatal care services among the mothers of Nepal: analysis of Nepal Demographic and Health Survey 2011- BMC Women's Health 14:19; http://www.biomedcentral.com/1472-6874/14/19

4. Republic of Kenya (2011): National Orientation Package for Targeted Postnatal care for (Nurses, Midwives, Clinical Officers and Medical officers) Division of Reproductive, Health Ministry of Public Health \& Sanitation Old Mbagathi Road Nairobi www.drh.go.ke

5. Republic of Kenya (2012): Accelerating attainment of Health Goals: The Kenya Health Sector Strategic And Investment Plan - KHSSP July 2012 - June 2017; Published by: Ministry of Medical Services and Ministry of Public Health \& Sanitation; Afya House PO Box 3469 - City Square, Nairobi 00200, Kenya; Email: ps@health.go.ke; http://www.health.go.ke

6. Republic of Kenya (2012): National Guidelines for Quality Obstetrics and Perinatal Care; Division of Reproductive, Health Ministry of Public Health \& Sanitation Old Mbagathi Road Nairobi www.drh.go.ke.

7. National Orientation Manual for Health Providers (Nurses, Midwives, Clinical Officers and Medical officers) on targeted postnatal care. Division of Reproductive, Health Ministry of Public Health \& Sanitation Old Mbagathi Road Nairobi www.drh.go.ke.

8. Republic of Kenya (2012): Accelerating attainment of Health Goals: The Kenya Health Sector Strategic And Investment Plan - KHSSP July 2012 - June 2017; Published by: Ministry of Medical Services and Ministry of Public Health \& Sanitation; Afya House PO Box 3469 - City Square, Nairobi 00200, Kenya; Email: ps@health.go.ke; http://www.health.go.ke

9. WHO 2007 "Everybody business: strengthening health systems to improve health outcomes": WHO's framework for action; Geneva, Switzerland.

10. Republic of Kenya (2012): Kenya Health Sector Strategic Medium Term Plan (2013-2017). Published by the Ministry of Medical Services and Ministry of Public Health \& Sanitation, Afya House-Nairobi

11. Republic of Kenya (2005): Kenya Health Sector Strategic Plan- Published by the Ministry of Health, Afya House-Nairobi

12. Republic of Kenya (2007): Reversing the Trends in Health and Development Indicators, Community Strategy Implementation Guidelines for Managers of the Kenya Essential Package for Health at the Community Level, March 2007 - published by the Ministry of Health

13. Republic of Kenya (2009): National Reproductive Health and HIV and AIDS Integration Strategy; published by the Ministry of Health, August 2009-Nairobi.

14. Republic of Kenya (2007): National Reproductive Health Policy, Published by the Ministry of Health, Afya House-Nairobi

15. Elaine Charurat et al (2011): An Assessment of Postpartum Intrauterine Contraceptive Device Services in Embu, Kenya February 2011, Access USAID (Family Planning Initiative). 
16. Jhpiego (2014): MCHIP Kenya End-of-Project Report; October 1, 2009-September 30, 2014; produced by Jhpiego Kenya Country Office, Nairobi-Kenya

17. USAID (2014): Lessons Learned from the Scale-Up Experience of Six High-Impact Interventions in Reproductive, Maternal, Newborn, and Child Health (RMNCH) - June 2014

18. MCHIP Kenya End-of-Project Report; produced by Jhpiego Kenya Country Office, Nairobi-Kenya, 2014

19. National Orientation Manual for Health Providers (Nurses, Midwives, Clinical Officers and Medical officers) on targeted postnatal care. Division of Reproductive, Health Ministry of Public Health \& Sanitation Old Mbagathi Road Nairobi

20. Matthew F Chersich et al (2009): Maternal morbidity in the first year after childbirth in Mombasa Kenya; a needs assessment BMC Pregnancy and Childbirth 2009, 9:51

21. Khadija, W. (2011). Prevalence of postpartum depression using the edinburgh postpartum depression scale at The Aga Khan University Hospital, Nairobi (Unpublished master's dissertation).

22. Republic of Kenya (2010): Integrating the Management of STIs/RTIs into Reproductive Health Services, Pocket Handbook - February 2010, Nairobi, Republic of Kenya

23. Liambila W., Mullick S., Askew I., Broutet N., Mohammed I., Awuor C., Kigen B., Mutunga C. et al. 2010. Introducing and Pilot-testing the National Guidelines on Integrating the Management of STIs/RTIs into Reproductive Health Settings in Kenya; Population Council: Nairobi, Kenya.

24. Repositioning Postpartum Care in Kenya Safe Motherhood Policy Alert, April 2005,Population Council Kenya; Population Council: Nairobi, Kenya.

25. Republic of Kenya (2010): Kenya Demographic and Health Survey 2008-09. Kenya National Bureau of Statistics

26. Wanyoro AK et al (2014): Preliminary Results of a study on Assessing the Feasibility of Integrating Gender Based Violence Screening and Management into Focused Antenatal and Post Natal Care in Kenya.

27. Kenya National Bureau of Statistics (KNBS) and ICF Macro. 2010. Kenya Demographic and Health Survey 2008-09. Calverton, Maryland: KNBS and ICF Macro.

28. Wilson Liambila, Francis Obare, Chi-Chi Undie, Harriet Birungi, Shiphrah Njeri Kuria, Ruth Wayua Muia and Assumpta Matekwa (2013): The community midwifery model in Kenya: Expanding access to comprehensive reproductive health services at the community level: AFRICAN Journal of Midwifery and Women's Health, Oct.-Dec. 2013, Vol 7, No 4

29. Population Council (2010): Introducing and Pilot-testing the National Guidelines on Integrating the Management of STIs/RTIs into Reproductive Health Settings in Kenya; Population Council: Nairobi,

30. Obare Francis et al (2012): PVR Mapping for Kenya, December 2012 in Kenya - published by Population Council. 


\section{Appendices}

Appendix 1: Risk of dying during postnatal period by day and cause

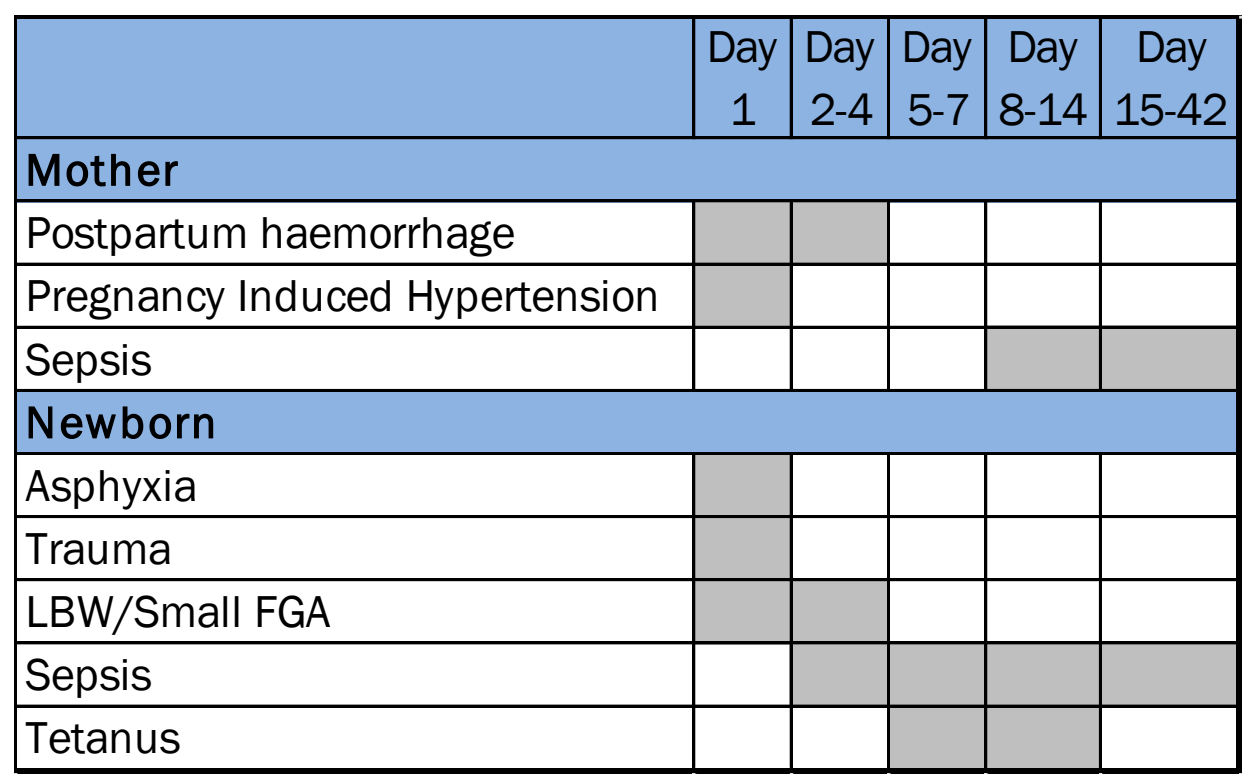

Source: World Health Organization (2010): Technical consultation on PPC and PNC -WHO/MPS/10.03, World Health Organization, 20

Avenue Appia, 1211 Geneva 27, Switzerland 
Appendix 2: Priority High Impact Interventions by level of care and age cohorts

\begin{tabular}{|c|c|c|}
\hline & Community based interventions & Facility based interventions \\
\hline Neonatal (HII) & $\begin{array}{l}\text { Sepsis } \\
\text { - } \quad \text { Hand washing with soap and water } \\
\text { - } \quad \text { Early and exclusive breastfeeding } \\
\text { - } \quad \text { Identification of danger signs and referral } \\
\text { LBW } \\
\text { - } \quad \text { As above } \\
\text { - Temperature management (kangaroo method) } \\
\text { Asphyxia } \\
\text { - Clear nose and throat for secretions }\end{array}$ & $\begin{array}{l}\text { Sepsis } \\
-\quad \text { Infection Prevention } \\
\text { - } \quad \text { Early and exclusive breastfeeding } \\
\text { - } \quad \text { Temperature management } \\
\text { - Antibiotics } \\
\text { LBW } \\
\text { - } \quad \text { As above } \\
\text { - Kangaroo method } \\
\text { Asphyxia } \\
-\quad \text { Neonatal resuscitation }\end{array}$ \\
\hline $\begin{array}{l}\text { Post neonatal up to } \\
5 \text { years (HII) }\end{array}$ & $\begin{array}{l}\text { Malaria } \\
\text { - Sleep under LLITN } \\
\text { - } \quad \text { Prompt diagnosis and treatment (iCCM) } \\
\text { Pneumonia } \\
\text { - Immunization } \\
\text { Diarrhea } \\
\text { Prompt diagnosis and treatment (iCCM) } \\
\text { - Hand washing with soap and water } \\
\text { Prompt diagnosis and treatment -iCCM (ORT - } \\
\text { - } \quad \text { Vitamins, Zn, Continued feeding) } \\
\text { Malnutrition } \\
\text { - } \quad \text { Breastfeeding } \\
\text { - Temperature Management } \\
\text { - } \quad \text { Vomplimentary feeding } \\
\quad \text { Vitamin A Therapeutic feeding }\end{array}$ & $\begin{array}{l}\text { Malaria } \\
-\quad \text { Sleep under LLITN } \\
-\quad \text { Testing and Rx of fever } \\
-\quad \text { ACTs for Malaria } \\
\text { Pneumonia } \\
-\quad \text { Immunization } \\
-\quad \text { Antibiotics } \\
\text { Diarrhea } \\
-\quad \text { Hand washing with soap and water } \\
-\quad \text { ORT (fluids, Zn, CT feeding) } \\
-\quad \text { Vitamin A } \\
\text { Malnutrition } \\
-\quad \text { Breastfeeding } \\
-\quad \text { Complimentary feeding } \\
-\quad \text { Vitamin A } \\
-\quad \text { Therapeutic feeding } \\
\text { HIV/ AIDS } \\
-\quad \text { Early infant diagnosis }\end{array}$ \\
\hline $\begin{array}{l}\text { Maternal mortality } \\
\text { (Indirect Causes) }\end{array}$ & $\begin{array}{l}\text { Anemia } \\
\text { - } \quad \text { Iron /folic acid supplementation } \\
\text { - } \quad \text { De-worming (hookworm) } \\
\text { - } \quad \text { Prompt Malaria Rx } \\
\text { - } \quad \text { Blood transfusion } \\
\text { Malaria } \\
\text { - } \quad \text { Sleep under LLITN } \\
\text { - IPTp } \\
\text { - } \quad \text { Prompt malaria diagnosis and Rx } \\
\text { HIV/AIDS } \\
-\quad \text { PMTCT } \\
-\quad \text { HCT } \\
\text { - } \quad \text { ARVs for mother }\end{array}$ & $\begin{array}{l}\text { Anemia } \\
-\quad \text { Iron /folic acid supplementation } \\
-\quad \text { De-worming } \\
\text { - Identify danger signs and refer } \\
\text { Malaria } \\
\text { - Sleep under LLITN } \\
-\quad \text { Identify danger signs and refer } \\
\text { HIV/AIDS } \\
-\quad \text { HCT }\end{array}$ \\
\hline $\begin{array}{l}\text { Maternal mortality } \\
\text { (Direct Causes) }\end{array}$ & $\begin{array}{l}\text { Hemorrhage (PPH) } \\
-\quad \text { Individualized Birth Plan } \\
\text { - Emergency preparedness } \\
\text { Sepsis } \\
\text { - As above } \\
\text { - Hand washing } \\
\text { Eclampsia } \\
\text { - As above } \\
\text { - ANC }\end{array}$ & $\begin{array}{l}\text { Hemorrhage (PPH) } \\
-\quad \text { AMTSL } \\
-\quad \text { MVA } \\
-\quad \text { Manual removal of placenta } \\
\text { Sepsis } \\
\text { B IV Antibiotics } \\
-\quad \text { Infection Prevention } \\
\text { Eclampsia } \\
-\quad \text { Magnesium sulphate } \\
-\quad \text { Calcium supplementation }\end{array}$ \\
\hline Maternal (Other) & $\begin{array}{ll} & \text { Verbal Autopsy } \\
\text { - } & \text { Family Planning } \\
\text { - } & \text { Maternal nutrition }\end{array}$ & $\begin{array}{ll}\text { - } & \text { MDR } \\
\text { - } & \text { Family planning - LAPMs } \\
\text { - } & \text { Partograph }\end{array}$ \\
\hline
\end{tabular}

Source: Republic of Kenya (2012): Priority High Impact Interventions by level of care and age cohorts, DRH, MOH, Nairobi, Kenya 


\section{Appendix 3: A Best Practice in integrating STIs/RTIs into Postnatal care Integrating}

\section{STI/RTI Management in Postnatal Care}

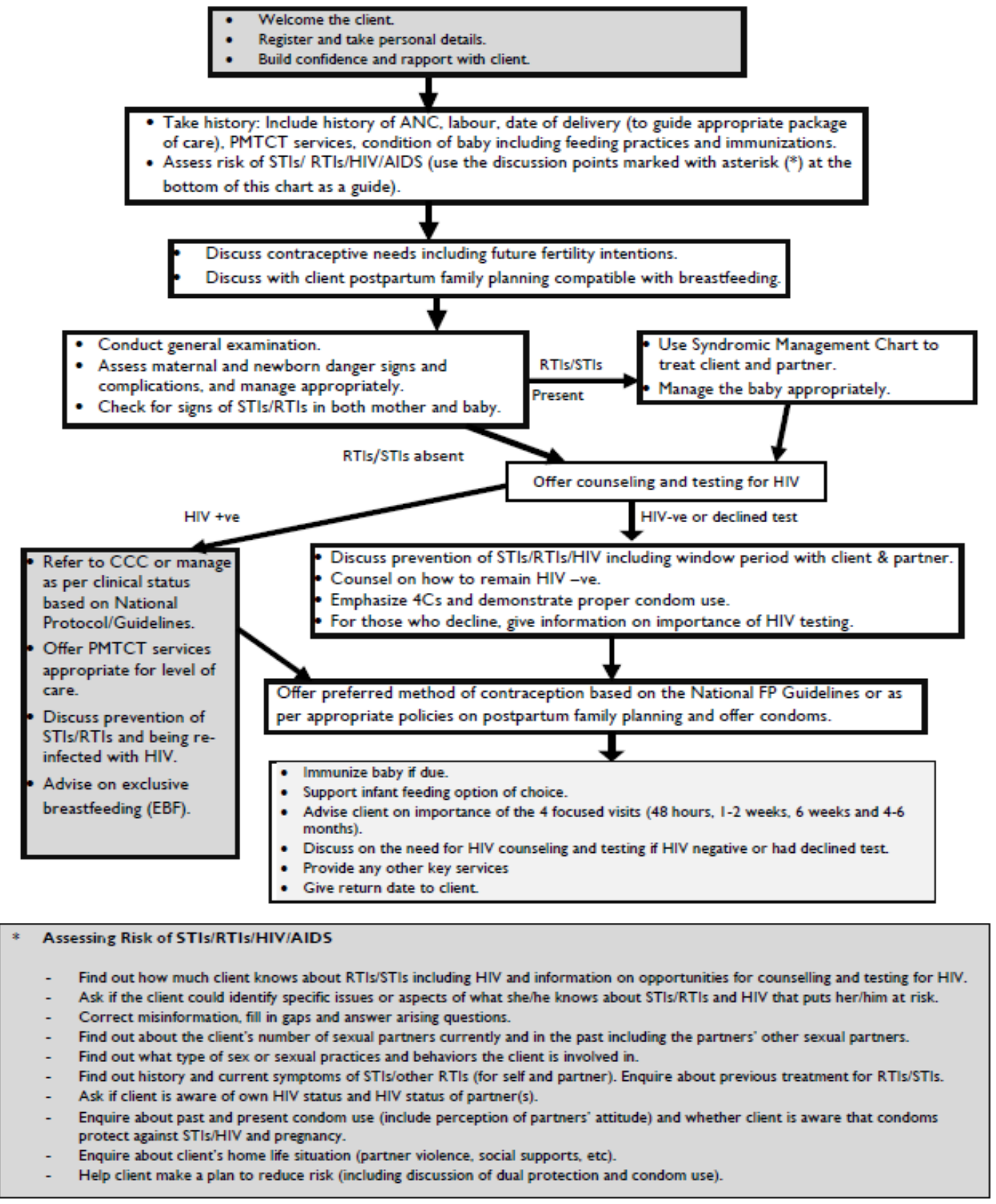

Republic of Kenya (2010): Integrating the Management of STIs/RTIs into Reproductive Health Services, Pocket Handbook - February 2010, published by National AIDS and STD Control Programme (NASCOP) and Division of Reproductive Health. Ministrv of Health. Nairobi 


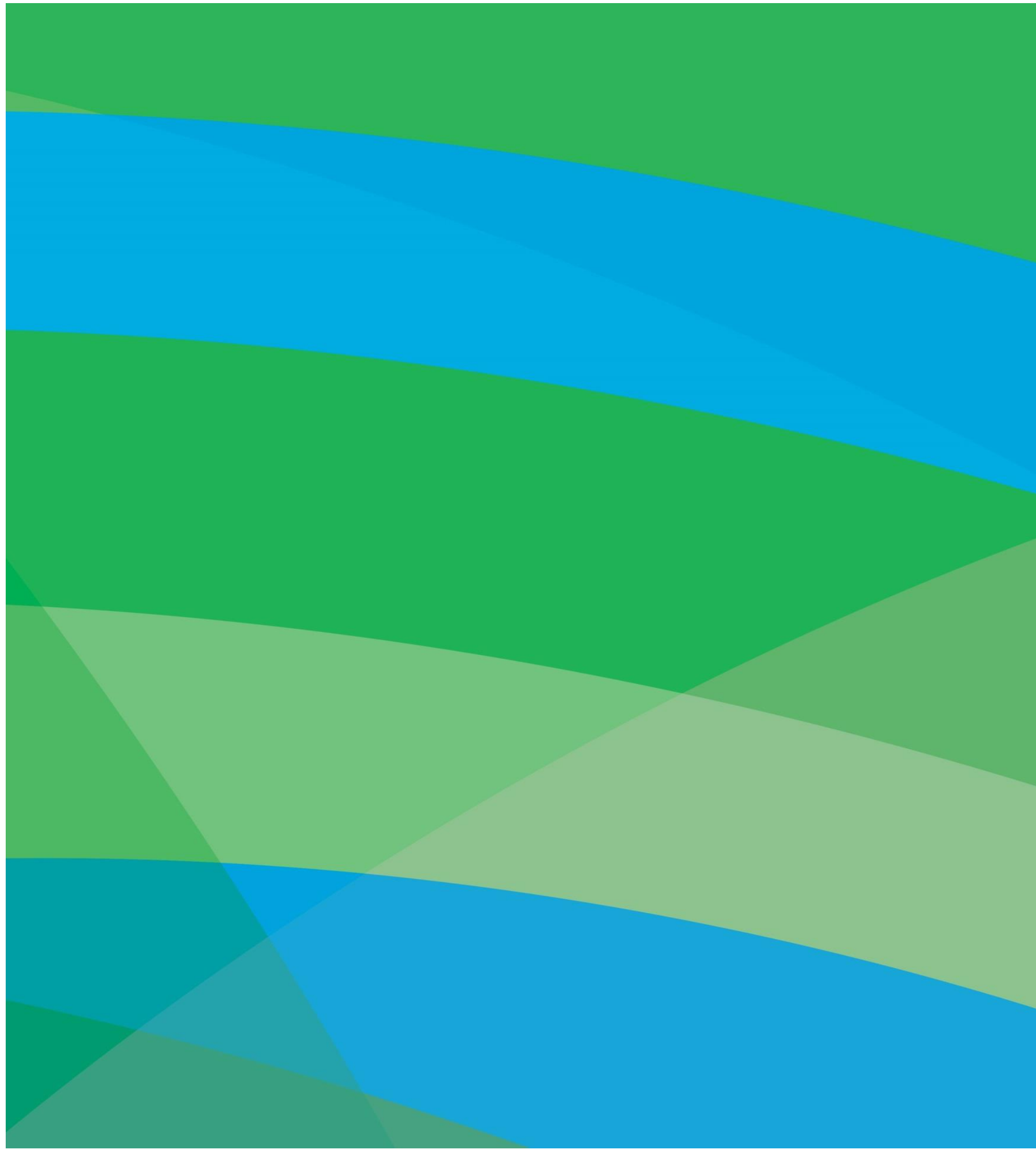

